\title{
UNTERSUCHUNGEN \\ AM SUBNIVALEN FORMENSCHATZ IN SPITZBERGEN UND IN DEN BÜNDNER ALPEN *
}

\author{
Gerhard Furrer
}

Entscheidend für die Bildung von Solifluktionsformen (vgl. Lit. 3, S. 273 und Troll, Lit. 10) ist periodisch auftretender Bodenfrost. Dieser ist besonders nahe der Schneegrenze, im subnivalen Bereich, morphologisch wirksam. Strukturböden und Fließerdeformen treten in den Polarzonen wie im Hochgebirge der gemäßigten und tropischen Breiten auf. Ein Ziel dieser Arbeit ist daher eine vergleichende Untersuchung des subnivalen Formenschatzes einer Region unserer Alpen mit demjenigen einer arktischen Landschaft.

1954 veröffentlichte PosER eine Karte der jetztzeitlichen Periglazialerscheinungen der Zillertaleralpen (Lit. 8). Diese Arbeit verfolgt den Zweck, im Rahmen des Arbeitsprogrammes der Kommission für Periglazialmorphologie der IGU einen Fortschritt in der Kenntnis der jetztzeitlichen Periglazialerscheinungen zu erzielen. Es stellt sich nun das Problem, inwiefern Posers Erkenntnisse auf den Nationalpark und seine umliegenden Gebiete übertragen werden können. Da Posers Karte noch keine andere aus den Alpen zu Vergleichszwecken gegenübersteht, muß bei ihrer Auswertung hinsichtlich Gesetzmäßigkeiten der Verbreitung und Standorte von Periglazialformen Zurückhaltung geübt werden.

Das Problem der Verbreitung ist zunächst rein morphographischer Natur und läßt sich durch Kartierung lösen. Kartierung setzt eine Legende voraus, wobei sich zeigt, daß jene der IGU, mit der Poser gearbeitet hat, stärker zu differenzieren ist.

Zur Kartierung haben Karten im M 1:4000 gute Dienste geleistet. Dieser Maßstab wird der starken Differenzierung der Legende gerecht. Die Wahl des Maßstabes muß noch 2 andern Tatsachen Rechnung tragen:

- häufig sind nur kleine Flächen gemustert

- oft wechseln Formen und 'Typen auf kleinstem Raum (vgl. Fig. 20 und 26)

Alle vorliegenden Kartierungen sind analytisch, auf synthetische Karten wurde, weil noch wenig Beobachtungsmaterial vorliegt, verzichtet.

\section{KINGSBAY AN DER WESTKÜSTE SPITZBERGENS $79^{\circ} \mathrm{N}, 28.6 .-13.7 .1956$}

DIE FORMEN VON PROFIL 1 (Fig. 1)

Die Formen des Profils werden in der Reihenfolge vom Meer (links) zum Gletscher (rechts) beschrieben. Rechts im Profil erkennt man den Hang der aktiven Endmoräne.

\section{Steinringe (Fig. 2 und 3)}

Kreisförmige, gelegentlich ovale Steinwülste umgrenzen Feinerdeflächen von $1-2 \mathrm{~m}$ Durchmesser. Manchmal sind die Wülste (Fig. 3) nicht zum Ring geschlossen, sondern bilden mehrfach gewundene Schleifen.

Die aus kantigen Steinen aufgebauten und feinerdefreien Wülste messen durchschnittlich $50 \mathrm{~cm}$ in der Breite. Berühren sich 2 benachbarte Formen, so kann sich dieser Betrag verdoppeln. Oft sind die Steinrahmen von unregelmäßigen Vegetations-

* Publiziert mit Unterstützung des Schweizerischen Nationalfonds zur Förderung der wissenschaftlichen Forschung. 


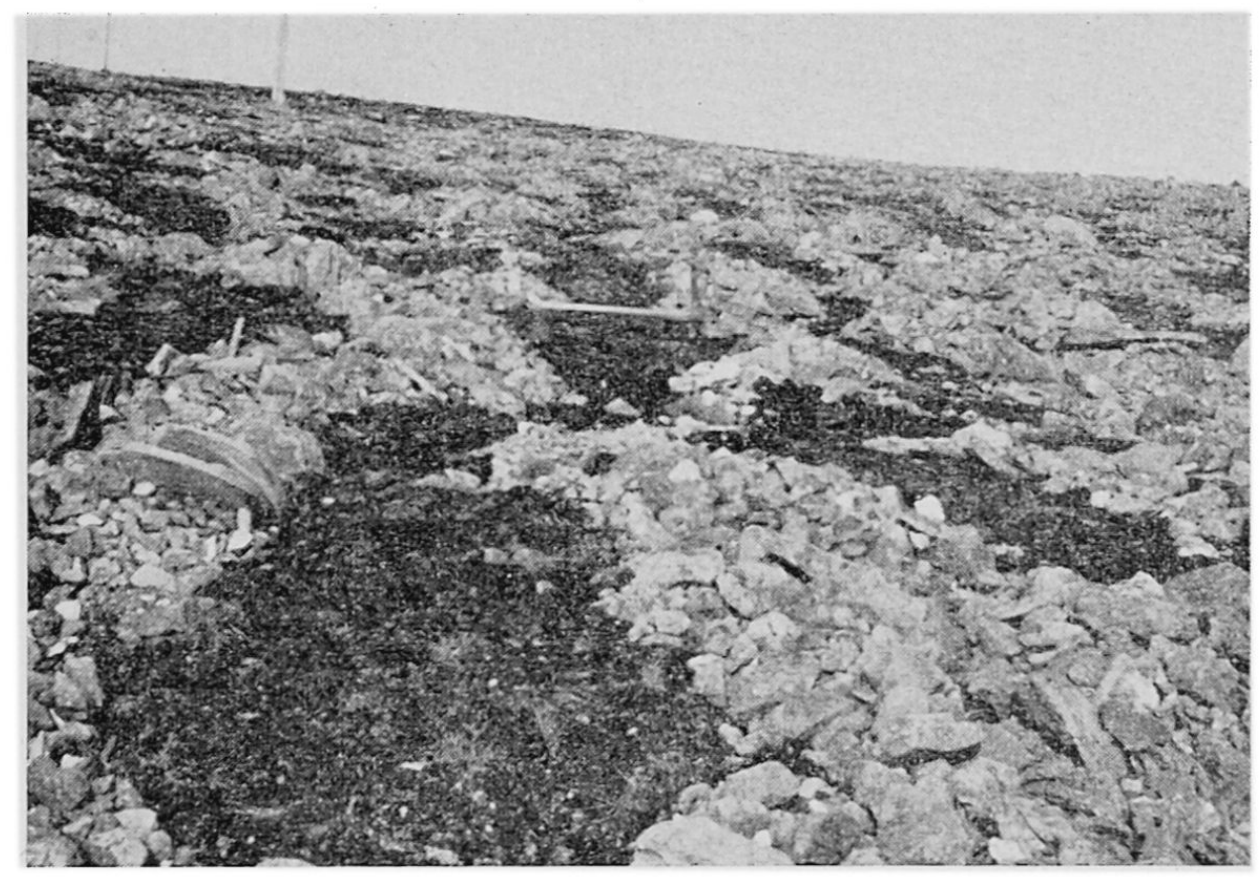

Abb. 1. Übergang von Steinpolygonen (Steinnetzboden) in Steinstreifen (vorn=unten). Ny Alesund (Fig. 1, Profil 1). Länge des Pickels $95 \mathrm{~cm}$. Die Steinrahmen und -streifen überragen die Feinerdeflächen wulstartig.

wülsten begleitet, stellenweise sogar von trockenem Moos und Flechten bedeckt. Polsterpflanzen, Moos und Gräser trifft man auch inselartig auf den Feinerdezentren und zwischen den Steinringen.

Die Wand der Steinrahmen ist mit kleinen Steinchen ausgekleidet, die teilweise an den Vegetationswülsten festkleben, während die größten Steine mehr in der Rahmenmitte $\mathrm{zu}$ finden sind.

Der Dauerfrostboden besteht an seiner Oberfläche aus hartem, weißem Eis $(1 / 11$ des Volumens im Standzylinder: mineralische Bestandteile). Die Grenzfläche zwischen der skelettarmen, breiartigen Feinerde und der Tjäle ist schwach konkavuhrglasförmig; unter den Rahmen folgt eine Aufwölbung des Eises.

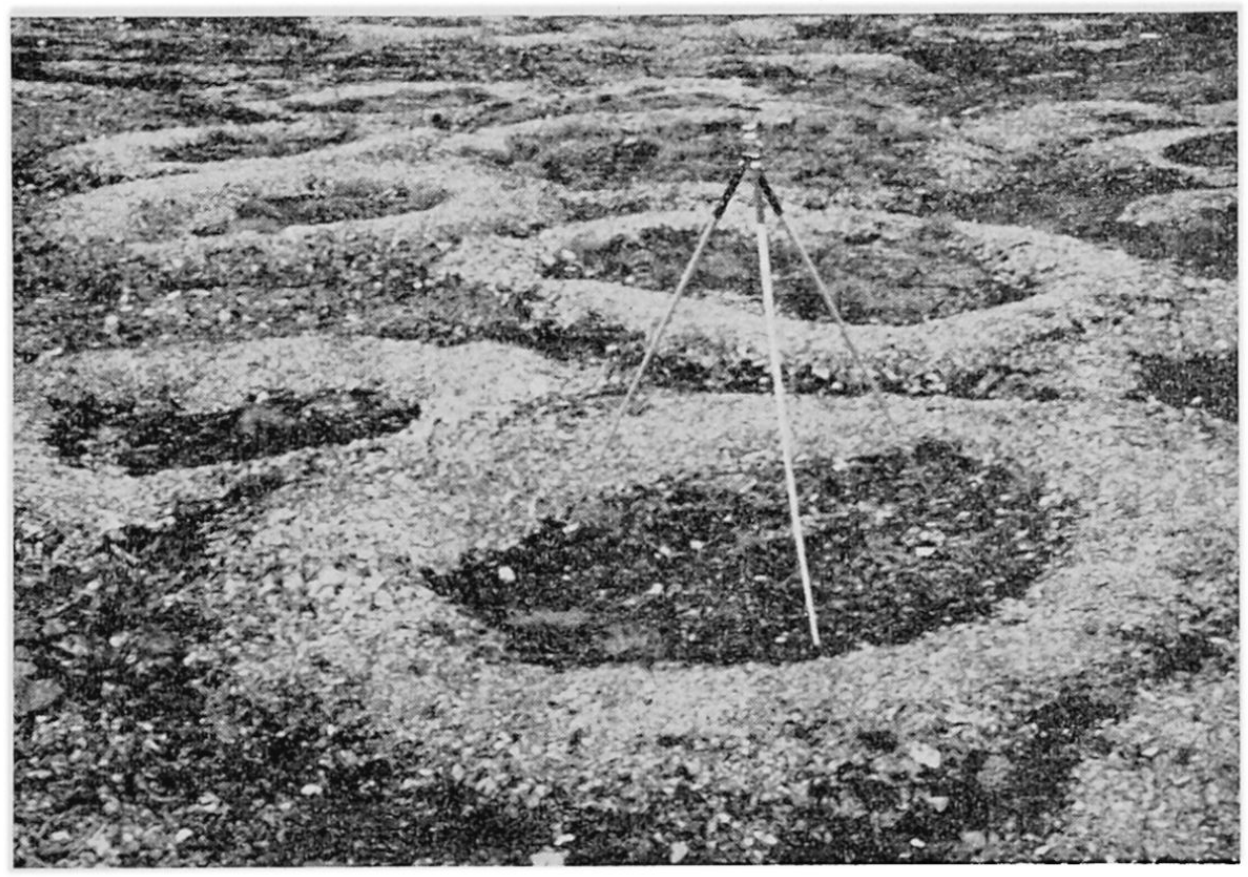

Abb. 2. "Amundsensteinringe" $\mathrm{Ny}$ Alesund (vgl. Fig. 14). Die $3 \mathrm{FuB}$ punkte des Stativs begrenzen ein gleichseitiges Dreieck von $1 \mathrm{~m}$ Seitenlänge. - Die seitliche Bewachsung der wulstartigen Steinrahmen ist stärker als bei jenen von Abb. 1. 
Abb. 3. Steinring. Sverdruphamaren Longyear, Fig. 20) Länge des Spatens $60 \mathrm{~cm}$. - Beachte die Kantenstellung, die Lage der Vegetation v. a. am Innenrand des Steinrahmens und die Rißpolygone der Feinerdefläche. Eine durchaus „alpine“Form!

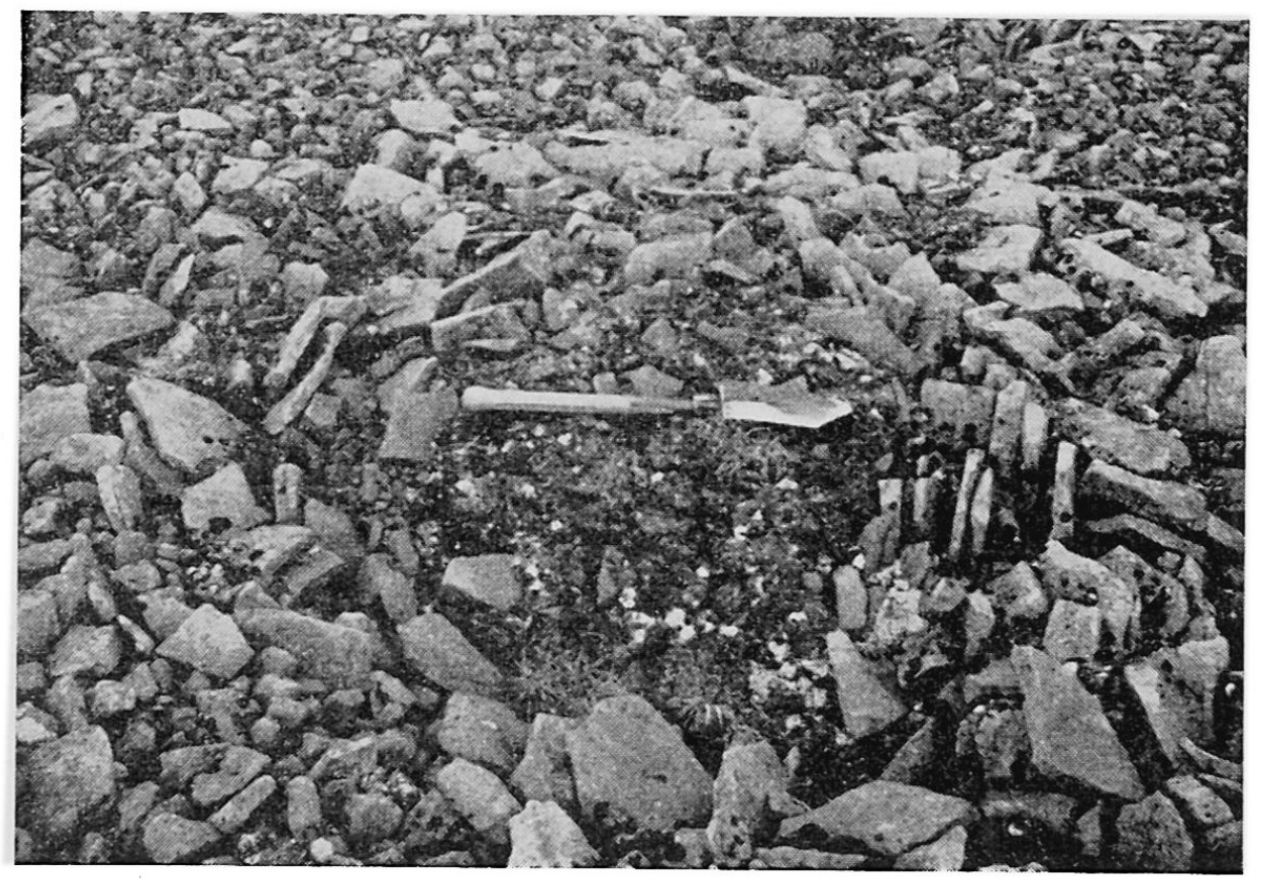

\section{Steinstreifen (Fig. 4)}

Im Abstand von $1-1,5 \mathrm{~m}$ ziehen sich Steinstreifen in der Fallinie gegen einen Bach. Die Hangneigung beträgt $8-10^{\circ}$. Bergseits verschwinden die Streifen unter Schneeflecken, die reichlich Wasser liefern. Dieses fließt über die ganze Fläche, ohne Furchen zu bilden und kann daher den ganzen Boden durchtränken. Diese Fließerde bildet zwischen den Steinstreifen langgezogene Zungen. Auf ihnen liegen vereinzelt Steine, die häufig durch Frostsprengung zerlegt sind. In den Steinstreifen murmelt Wasser; stehen kann man nur auf Steinen.

Die Streifen verlaufen nicht immer geradlinig, oft vereinigen sich 2 benachbarte in einem spitzen Winkel. Im Gegensatz zu den wulstig aufgesetzten Rahmen der oben beschriebenen Ringe liegen die Steinstreifen in der Feinerde eingebettet. Das Graben war in der steinarmen Feinerde unmöglich, da die breiartige Fließerde sofort wieder zu-

Fig. 1. Drei Profile aus dem Raume Ny Alesunds. Profilverlauf siehe Fig. 17.
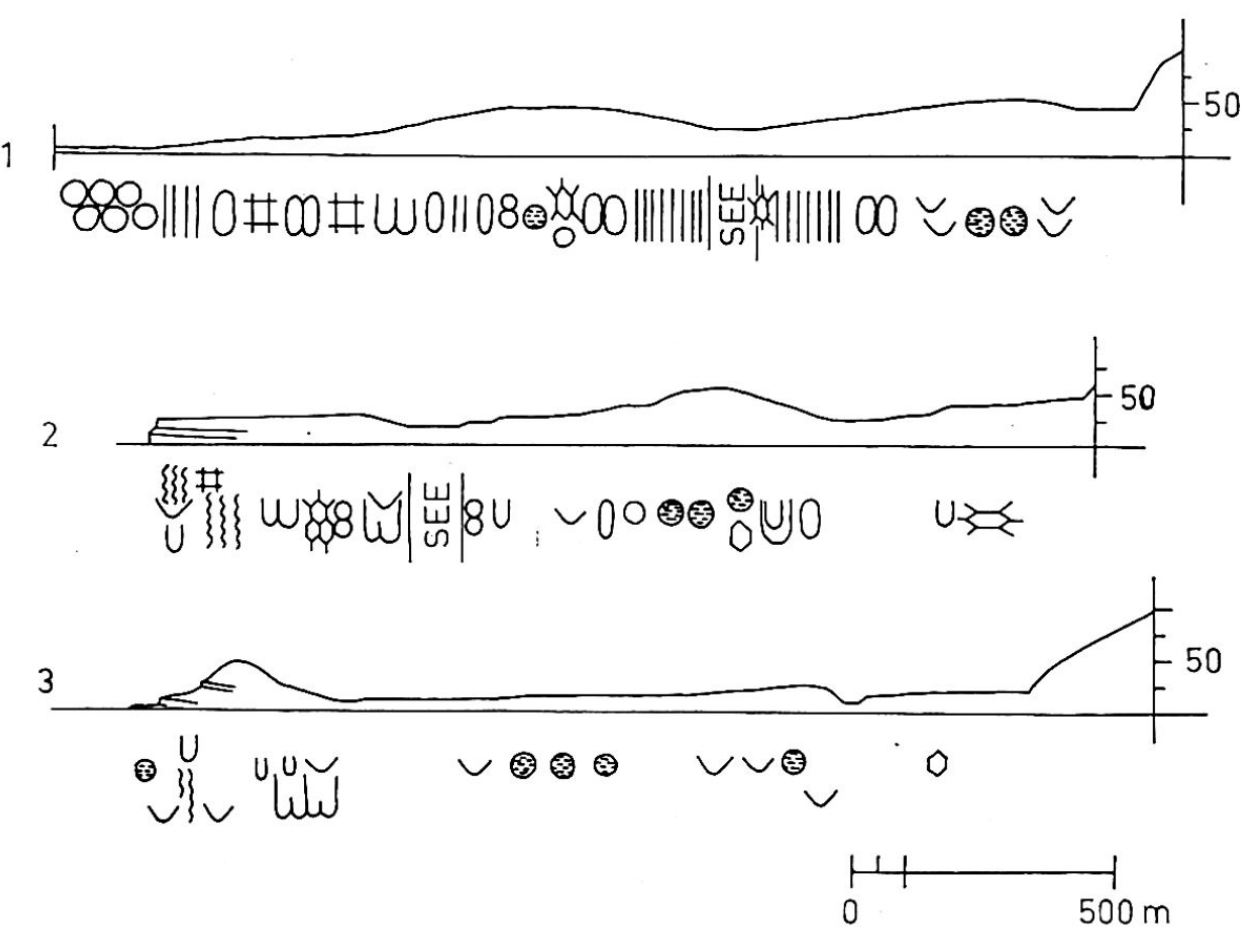
$\begin{array}{ll}\text { große } & 1: 10000 \\ \text { Maßstäbe } & \text { u. kleiner }\end{array}$

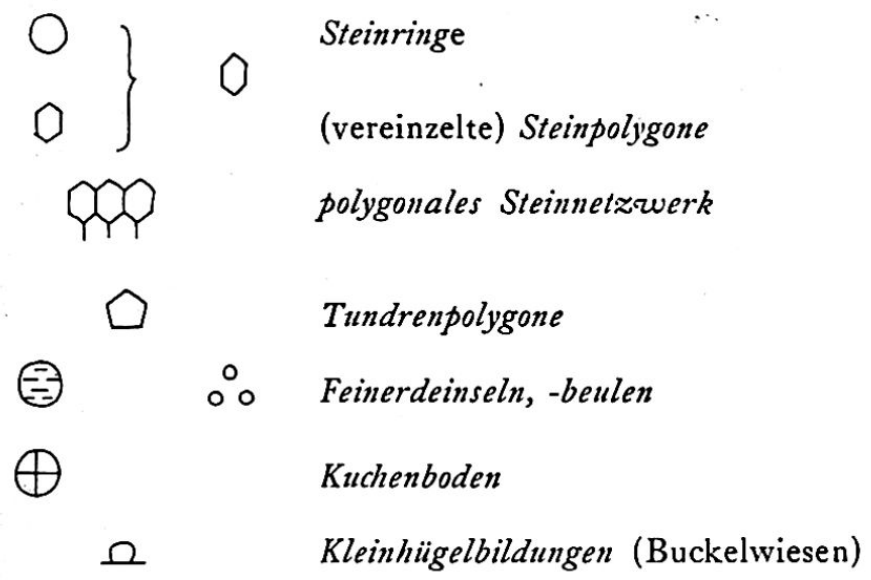

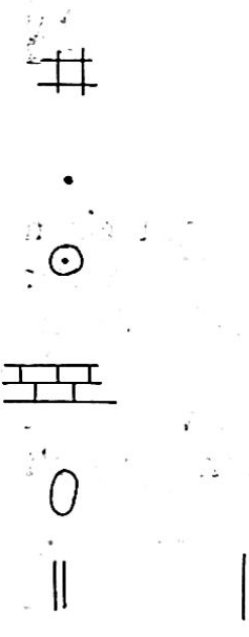

Zellenboden $(5-30 \mathrm{~cm}$ Seitenlänge der Spalten- oder Rißpolygone, mit und ohne Steinfüllung der Risse)

Mintatursteinringe $( \pm 5 \mathrm{~cm} \varnothing)$

kleine Steinringe $( \pm 20 \mathrm{~cm} \varnothing)$

Pflasterboden

deformierte Steinringe

Steinstreifen

3

Erdstreifen (Miniaturform)

kleine Steinstreifen (Zwischenräume nicht so regelmäßig wie bei Erdstreifen und größer)

$\left.\begin{array}{c}\text { UI } \\ \text { II } \\ u\end{array}\right\}$

(große) Fließerdezungen (bewachsene und unbewachsene Stirn)

kleine Fließerde und Schuttzungen (Größe ähnlich Girlanden, unbewachsene Stirn)

Girlanden

sammensackte. Hatte man endlich ein Loch freigelegt, so füllte es sich gleich wieder mit Wasser. Bis wenige $\mathrm{cm}$ über dem Dauerfrostboden sind die Steinstreifen feinerdefrei, die faustgroßen, meist kantigen Trümmer scheinen regellos gelagert. Entfernt man die Steine, so füllt ein rasch fließendes Bächlein ihr Bett.

Wie Fig. 4 zeigt, erreicht die Steinfüllung nicht unmittelbar die Tjäle, eine Feinerdeschicht ist dazwischen eingeschaltet. Im Gegensatz zur ersten Form bildet sich unter der Steinmasse eine deutliche Rinne im gefrorenen Boden, während dieser unter den Feinerdestreifen sich aufwölbt bis $5-15 \mathrm{~cm}$ unter die Oberfläche. 


\section{Deformierte Steinringe (Fig. 5 zeigt einen Rahmenquerschnitt)}

Hangneigung $6-8^{\circ}$. - Die Feinerde ist schwächer wasserdurchtränkt als bei den oben beschriebenen Streifen, dagegen ist sie von einer dichten Gesteinsspreu bedeckt, trägt Flechten und Moospolster. Der Umriß der Form erinnert an eine Birne. Ein Vertreter wies folgende Dimensionen auf (Maße der Feinerdefläche) :

$\begin{array}{ll}\text { Längsachse in der Fallinie } & 1035 \mathrm{~cm} \\ \text { Durchmesser senkrecht dazu: } & \\ \text { a } 2 \mathrm{~m} \text { vom oberen Ende } & 110 \mathrm{~cm} \\ \text { b } 4 \mathrm{~m} & 295 \mathrm{~cm} \\ \text { c } 6 \mathrm{~m} & 285 \mathrm{~cm} \\ \text { d } 8 \mathrm{~m} & 355 \mathrm{~cm}\end{array}$

Um die Auftautiefe festzustellen, wurden folgende Messungen vorgenommen:

1. an allen Schnittpunkten der Längsachse mit den Durchmessern a - d

2. an den Enden der Durchmesser

$\begin{array}{cccc}\text { rechtes Durch- } & \text { Längsachse } & \begin{array}{c}\text { linkes Durch } \\ \text { messerende }\end{array} \\ \text { oberes Ende } & 11 \mathrm{~cm} & 13 \mathrm{~cm} & \\ \text { a } & 14^{1 / 2 \mathrm{~cm}} & 15 \mathrm{~cm} & 13 \mathrm{~cm} \\ \text { b } & 16 \mathrm{~cm} & 20 \mathrm{~cm} & 14 \mathrm{~cm} \\ \text { c } & 17 \mathrm{~cm} & 22 \mathrm{~cm} & 19 \mathrm{~cm} \\ \text { d } & & 21 \mathrm{~cm} & 19 \mathrm{~cm} \\ \text { unteres Ende } & & 12 \mathrm{~cm} & \end{array}$

Aus diesen Zahlen geht hervor, daß die Oberfläche des Feinerdezentrums und des Dauerfrostbodens wie bei den Steinringen (Fig. 2) gegensinnig gewölbt sind. Die Feinerde ist von einer dünnen, ausgetrockneten Kruste überzogen, die durch Rißpolygone gegliedert ist. Die feinen Riße enthalten teilweise Steinchen.

Gelegentlich kann man beobachten, wie ein Steinwulst seinen talseitigen Nachbarn überflossen hat. Bergseits sind die Rahmen schwach entwickelt und oft von Vegetation bedeckt. Einen eigentlichen Steinwulst wie bei den Steinringen (Fig. 3) trifft man nur seitlich und am talwärtigen Bogen. Der die Steinrahmen begleitende Vegetationswulst ist am Innenrande stark ausgebildet, während er außen (Fig. 5

FIG 2

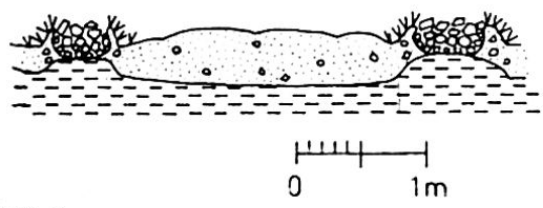

FIG 3

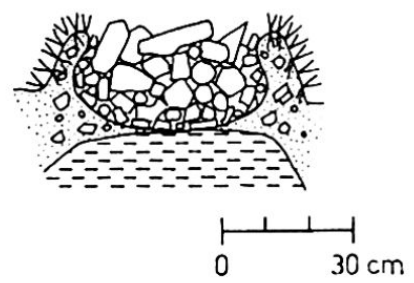

FIG L
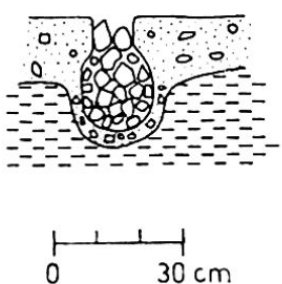

FIG 5

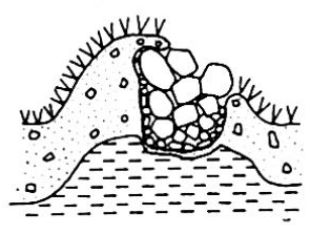

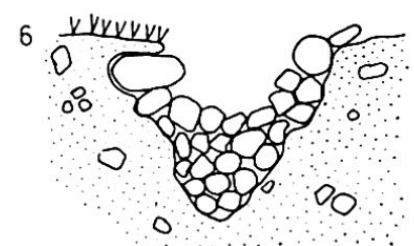

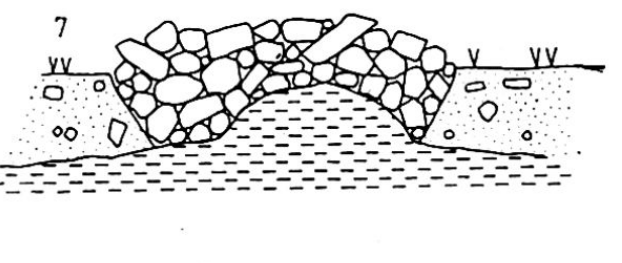

Fig. 2 Profil durch einen Steinring. Punktiert: Feinerde. Gestrichelt: Frostboden. V: Vegetation. Fig. 3 Profil durch den Wulst des Steinrings von Fig. 2. Fig. 4 Profil durch einen Steinstreifen. Fig. 5 Profil durch einen Wulst eines deformierten Steinringes. Gefälle von links nach rechts. Fig. 6 Profil durch den Steinrahmen zweier benachbarter Polygone. Fig. 7 Profil durch den Steinrahmen eines schwach deformierten Polygons. Hangneigung $3^{\circ}$ (Profil 5 liegt in der Fallinie, Profil 7 verläuft senkrecht zu ihr). 
rechts) oft kaum feststellbar ist. Vergleicht man Fig. 3 mit Fig. 5, so verdient die Form der Frostbodenoberfläche im Bereiche des Steinrahmens Beachtung: Eine seichte Rinne hat sich in der Kulmination der Tjäleaufwölbung gebildet.

4. und 6. Kleinmaschige Vegetationsnetze (Durchmesser $30-70 \mathrm{~cm}$, Breite der Vegetationsrahmen $5-10 \mathrm{~cm}$, Auftautiefe $30-40 \mathrm{~cm}$ )

Auf einer horizontalen Fläche mit ziemlich dichter Vegetationsdecke ist der Boden oberflächlich trocken und von unregelmäßig verlaufenden Rissen von wenigen $\mathrm{mm}$ Breite durchzogen. Stellenweise bilden diese Polygone. Vorwiegend an den Rissen siedelt sich Vegetation an; in richtigen Wülsten überragt sie die ebenen Feinerdezentren, die dicht mit feinen Steinchen übersät sind.

5. Schwach deformierte Steinringe und -schleifen (Stellenweise vollständig überwachsene Rahmen, Steinrahmen wie Fig. 3)

Die einige $\mathrm{cm}$ mächtige Wurzelschicht mit fast schwarzem Humus und wenig Steinchen ist leicht von den Steinwülsten abhebbar. Von beiden Seiten her überwachsen die Vegetationsränder die Steinrahmen immer mehr. Oft sind diese nicht wulstartig, sondern ihre Oberfläche liegt auf ungefähr gleichem Niveau wie die Feinerdezentren. Die Steine sind dann in Rinnen mit ziemlich steilen Wänden versenkt. Unter der ausgetrockneten Oberfläche der Zentren ist die skelettarme Feinerde feucht.

\section{Fließerdezungen (Breite 6-10 m, Länge über $10 \mathrm{~m}$ )}

Die Fließerdestirn ist gegenüber ihrer Umgebung nur um wenige $\mathrm{cm}$ erhöht. Sie wird von einem Steinrahmen begleitet, in dem Wasser zirkuliert. Große, kantige Steine sind als Rahmen tangential zur Stirnkontur angeordnet. Sie stammen von der benachbarten, höher gelegenen Wallmoräne und liegen auf dem Anstehenden. Kurze Wülste, teilweise überwachsen, parallel zum Zungenrand verlaufend, gliedern die Rückenfläche.

\section{Deformierte Steinpolygone (Fig. 6)}

Ihre Längsachsen liegen in der Fallinie. Man mißt Formen von $110 \times 180$ bis $300 \times 900 \mathrm{~cm}$ Durchmesser. Die Oberfläche der Feinerdezentren ist mit feinen Rissen durchsetzt, die - teilweise mit feinen Steinchen gefüllt - Miniaturpolygone bilden. Diese Risse reichen $6-11 \mathrm{~cm}$ in die Tiefe. Unterhalb derselben wird die Feinerde feucht. Fig. 6 zeigt einen Querschnitt durch den Steinrahmen zweier benachbarter Formen. Stellenweise sind diese stark überwachsen. Der trennende Graben kann - besonders beim Zusammentreffen dreier Steinringe - mit groben, kantigen Trümmern gefüllt sein. Die Korngröße der Steinfüllung nimmt nach der Tiefe ab. Zwischen den Steinen zirkuliert Wasser. Als Auftautiefe wurden in den Polygonzentren Werte bis $70 \mathrm{~cm}$ gemessen.

\section{Steinstreifen}

Die leicht gewundenen Streifen folgen der Fallinie. Stellenweise sind sie dem Gelände nicht aufgesetzt wie beispielsweise die Rahmen von Fig. 5 oder 12, sondern versenkt wie in Fig. 8.

\section{0. und 11. Mehr oder weniger stark deformierte Steinringe}

Man sieht sehr schön, wie sich der Übergang von Ringen zu Ovalen mit zunehmender Hangneigung vollzieht, wie übrigens auch auf dem andern Abhang der Moräne (13.-15.). 

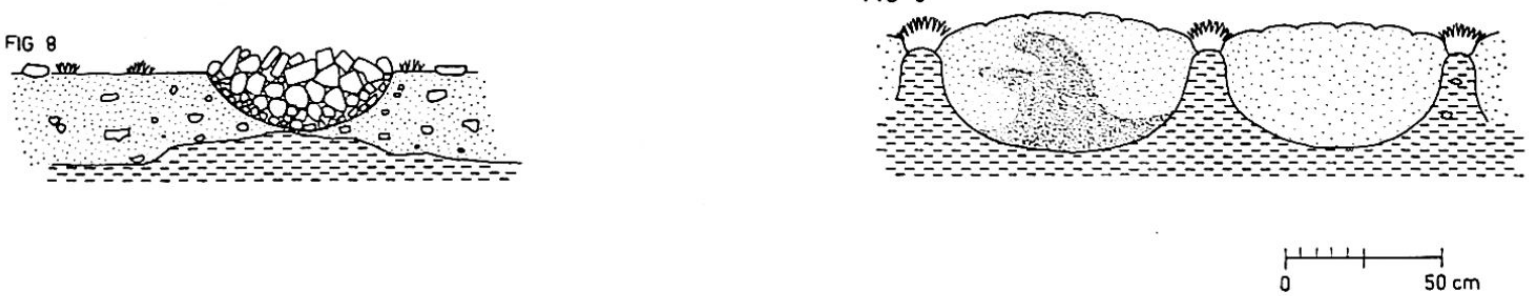

Fig. 8 Profil durch einen Steinstreifen (Hangneigung $8^{\circ}$ ). Fig. 9 Profil durch 2 Feinerdeinseln. Eng punktiert: rötliche Feinerde. Weit punktiert: grau-braune Feinerde.

\section{Feinerdeinseln}

$\mathrm{Zu}$ oberst auf der Moränenkuppe unterbrechen kreisförmige Feinerdeinseln die allgemeine Schuttbedeckung, ohne daß sich eigentliche Steinringe bilden. Die schwache Wölbung ist durch Rißpolygone (Zellenboden) gemustert. Entgegen der Beobachtung bei Form 20 konnte hier kein Eis festgestellt werden.

13.-15. Polygone, Steinringe und sich daraus entwickelnde Deformationsformen (Abb. 1)

Ein Steinnetzwerk aus groben Trümmern überzieht den Abhang zum See. Die Polygone werden bei zunehmender Hangneigung sogleich deformiert und gehen schließlich in leicht gewundene Streifen über. Zwischen den letztgenannten ist gelegentlich noch eine Querverbindung feststellbar. Auf der flachen Moränenkuppe sind die Polygone mit Feinerdeinseln und Steinringen vergesellschaftet.

Hangneigung bei

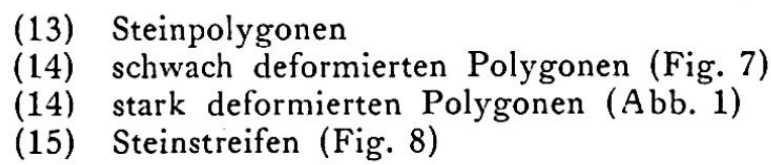

Die Trümmer in den Steinrahmen sind z. T. auffallend groß, kantig und ohne feststellbare Regelmäßigkeit eingeordnet. Im Gegensatz zu den Steinringen (1) fehlen Vegetationswülste entlang den Rahmen. Zwischen diesen liegen wenige Steine und vereinzelte Vegetationsinseln. Die Feinerde ist stark wasserdurchtränkt, besonders bei den untersten Formen.

Die größten Steine liegen in den flach U-förmigen Rahmen oben, während die Korngröße nach unten abnimmt. Die Rinnenwände sind mit kleinen, feuchten Steinchen ausgekleidet (Fig. 8), die an der Rinnenwand festkleben. In die Feinerdezentren sind einige wenige Steinchen eingestreut. Unter den Rahmen trifft man reines, weißes Eis. Im Zentrum der Feinerde mißt die Auftautiefe bis $30 \mathrm{~cm}$.

\section{Undeutliches Steinnetzwerk}

Leider ist es schlecht ausgebildet, aber die Größe der einzelnen Formen - Durchmesser um $3 \mathrm{~m}$ - fällt auf.

\section{Steinstreifen}

Breite, nur schwach gewundene Steinstreifen mit kantigen Trümmern bis zu $1 \mathrm{~m}$ Durchmesser gliedern eine mehrere Aren große Fläche. Bergwärts sind sie von mächtigen Schneeflecken bedeckt, welche die Feinerde so stark durchnässen, daß man nur auf den Steinstreifen marschieren kann. Am spätern Nachmittag rauschen zwischen den Steinen der Streifen «Schmelzwasserbäche». An ihrem untern Ende gehen diese Strei- 
fen in Steinnetze (16) über. Die meist mehr als $1 \mathrm{~m}$ breite Feinerde zwischen den Streifen ist durch Fließerdewülste gegliedert.

\section{Deformiertes Steinnetzwerk}

19. Girlanden (Beschreibung siehe Profil 2)

\section{Feinerdeinseln (Fig. 9)}

Von Schneeflecken genährte Durchtränkungsfließerde und mit Wasser vollgesogene Moospolster charakterisieren die teilweise bewachsene Moräne. Auf ihr findet man kreisrunde, vegetationsfreie Feinerdeflächen, die schwach beulenartig gewölbt sind. In kleinen Mulden und auf nur leicht geneigten Flächen ist ihre Oberfläche weich und feucht, auf Kuppen hart und durch feine Risse gegliedert, die mit Steinchen gefüllt sein können. Die an der Oberfläche ausgetrockneten Formen erkennt man an ihrer hellen Farbe. Bei starker Aufwölbung bilden sich in der Feinerde Spalten.

Mit zunehmender Hangneigung lassen sich Übergänge zu ovalen Formen, weiter hangabwärts zu Girlanden beobachten.

Die Mooswülste um die Zentren sind leicht abhebbar. Sie liegen ohne dazwischengelagerte Feinerde auf Eis. Die ungefrorene, skelettarme Feinerde füllt einen gefrorenen, steilwandigen Napf. Wo sich die Ränder dreier benachbarter Formen treffen, laufen auch 3 Eiswände zusammen. Mit dem Übergang zu Girlanden verschwindet das Eis.

Bei einem Beispiel fällt innerhalb der ungefrorenen Feinerde eine Struktur auf (Fig. 9, links), die sich dank ihrer verschiedenen Färbung - ein rötlicher, mehrfach gelappter Kern in der grau-braunen Umgebung - deutlich abhebt.

\section{DIE FORMEN VON PROFIL 2 (Fig. 1)}

In diesem und dem folgenden Profil werden nur diejenigen Formen beschrieben, die im 1. Profil noch nicht behandelt wurden oder die eine Besonderheit zeigen.

\section{1. und 2. Miniaturformen}

Der anstehende Fels über dem Meerufer wird von einer dünnen, lockeren Spreu seines Verwitterungsschuttes überzogen. In diesem Schutt treten auffallend häufig selbständige Miniaturformen auf, während sie andernorts hauptsächlich auf Polygonzentren und Girlandenrücken zu beobachten sind. Diese Muster gleichen den Miniaturformen der Alpen in allen Einzelheiten.

\section{a) Miniatursteinnetze und -streifen (Zellenboden)}

Eine Gruppe der Miniaturformen fällt durch unregelmäßige Größe der Felder Durchmesser 5-20 cm - bzw. unregelmäßigen Streifenabstand auf (vgl. dazu aus den Alpen in Lit. 3 die Abb. 12-14, 19, 26 und 32). Bei vielen Formen läßt sich nachweisen, daß die $2-3 \mathrm{~cm}$ breiten Steinrahmen aus Rissen hervorgegangen sind, die nachträglich mit kantigen Steinchen gefüllt wurden. Vom V-förmigen Steinrahmen zieht sich oft ein feiner, vertikaler Riß einige $\mathrm{cm}$ weiter in die Tiefe (vgl. aus den Alpen Lit. 6, Abb. 7, Fig. 3), auch wenn die angrenzende Feinerde weich und feucht ist. Gelegentlich gewinnt man den Eindruck, daß Steinstreifen aus Regen- oder Schmelzwasserracheln hervorgegangen sind.

b) Erdstreifen (Lit. 3, Abb. 25)

Ihr Muster - besonders, wenn sie auf Girlandenrücken auftreten - gleicht vollständig demjenigen der Alpen (vgl. Lit. 3, Abb. 33). Sie zeichnen sich durch Konstanz 
ihrer Dimensionen und streng parallelen Verlauf aus. Ihre charakteristische Eigenschaft, das stromlinienartige Umfließen größerer Steine - wobei sich die Streifen enger scharen - tritt deutlich in Erscheinung.

\section{Fließerdezungen}

\section{Sohlenständige Steinpolygone (Fig. 10)}

In klassisch schöner Ausbildung überzieht ein Netz von regelmäßigen Sechsecken den Boden (Länge der Diagonalen $\pm 1 \mathrm{~m}$ ). Die Steinrahmen sind gegenüber den planen Feinerdeflächen etwas versenkt und werden seitlich von einem Vegetationswulst begleitet, der sich ziemlich tief in das Rahmenbett hinabzieht. Die den Rahmen füllenden Steine reichen bis zu einem durchfeuchteten Steinbett hinab, das auch unter den Feinerdezentren verfolgt werden kann. Die Oberfläche der gefrorenen Zone verläuft mehr oder weniger parallel zur Polygonoberfläche.

\section{Steinringe}

6. Girlanden (Fig. 11)

Vom überschwemmten Seeufer mit sumpfigem, weichem Moosboden und undeutlichen Strukturen steigt der Hang mit $5-8^{\circ}$ an. In seiner oberen Region ist er ziemlich trocken, Pflanzen finden sich in Inseln und Streifen.

Im unteren Teil des Hanges treten Girlanden als sekundäre Gliederung der Fließerdezungen auf, wie man dies auch in den Alpen beobachten kann (Lit. 3, Abb. 38, 39, Fig. 7, S. 257). Darüber ist der Hang durch selbständige Girlanden deutlich getreppt (vgl. Lit. 3, Abb. 31). Manche sind fast völlig überwachsen, andere tragen auf ihrem Rücken einige Vegetationsinseln oder nur feinkörnigen Schutt, während ihr Stirnrand allgemein von Pflanzen bedeckt ist (Dryas, Pedicularis, Cerastium, Saxifraga, Salix, Carex und Moose). Die unbewachsenen Stellen der Girlandenrücken sind ausgetrocknet, tragen Risspolygone mit und ohne Steinfüllung.

Ein Profil entlang der Fallinie zeigt weitgehend mit unseren alpinen Formen Übereinstimmung: die Bewachsung, die dunkle, schwarz-braune Humusschicht - trocken, mit abgestorbenem Pflanzenmaterial - die an der Stirn deutlich verdickt ist und in mehreren Lappen bergwärts in die Girlande hineinzieht. Zwischen diesen Humusschichten ist gelbbraunes, sandiges, trockenes Material mit vereinzelten Steinchen eingelagert. In der Stirnregion fällt eine größere Ansammlung von Steinen auf, die teilweise mit einer lokal begrenzten Eislinse zusammengefroren sind. Eine Lage fast ausschließlich gröberer Steine schließt die Form in der Tiefe ab.

\section{Steinringe (Fig. 12, gleicher Typ wie Fig. 2 und 3)}

Auf einer außerordentlich stark wasserdurchtränkten Fläche breiten sich Steinringe um das nw Seende aus. Die bis $1 \mathrm{~m}$ breiten und $10-30 \mathrm{~cm}$ hohen Steinwülste sind manchmal nicht zum Ring geschlossen, sondern als gewundene Schleifen ausgebildet (häufiger als bei Form 1 in Profil 1). Die Trümmer der Wülste weisen eine auffallend gleiche Korngröße auf. Die Feinerdezentren sind fast vollständig steinfrei und vereinzelt mit Flechten und Moosen bedeckt. Bei einigen Formen sind die Zentren schwach gewölbt und von feinen Rissen durchsetzt.

Eine Schicht aus Humus und Würzelchen begleitet die Steinrahmen seitlich, ist sogar als $1-2 \mathrm{~cm}$ breites, dunkles Band bis ins Eis hinunter verfolgbar, das auffallend klar und weiß ist. Steine des Rahmens sind z. T. so fest damit zusammengefroren, daß sie kaum losgepickelt werden können. Aus ihrer Anordnung kann man auf die eigentliche Form des «Grabens» schließen. Die Oberfläche der Tjäle, die unter den Zentren in $20 \mathrm{~cm}$ Tiefe erreicht wird, nimmt einen ähnlichen Verlauf wie bei Fig. 2: wannen- 

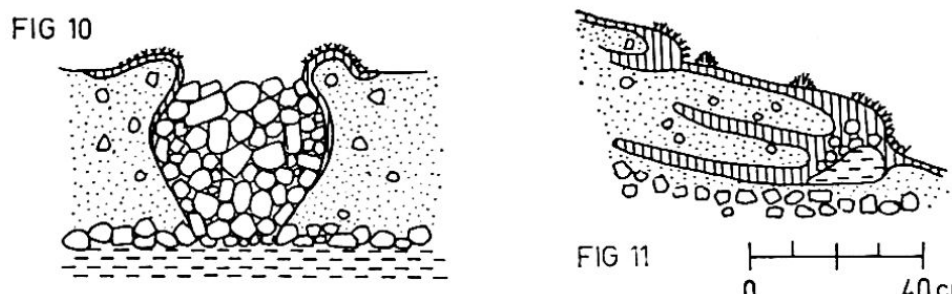

FIG 11
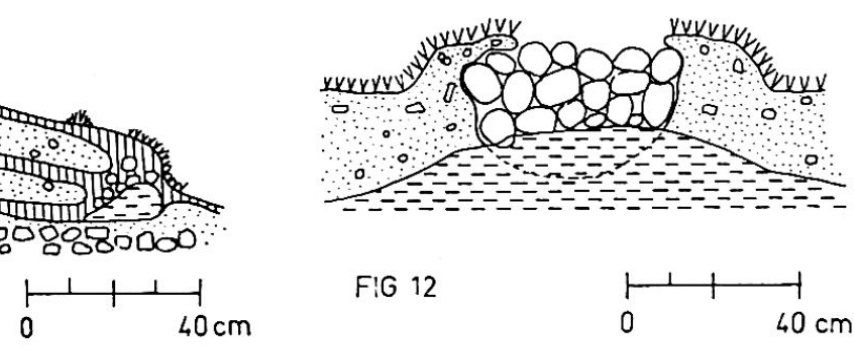

Fig. 10 Profil durch den Rahmen zweier sohlenständiger Steinpolygone. Senkrecht schraffiert: Vegetationswulst (an Oberfläche), dunkel-braune, humose Schicht (darunter). Fig. 11 Profil entlang einer Fallinie durch eine Girlande (der Maßstab gibt die Horizontale an). Senkrecht schraffiert: dunkle schwarzbraune Humusschicht, horizontal gestrichelt: Eislinse. Fig. 12 Profil durch den Rahmen eines Steinrings. - Starke randliche Überwachsung. Die Rahmensteine sind so fest mit dem Eis zusammengefroren, daß die Form der Rahmensohle nicht exakt festgelegt werden kann (gestrichelt).

förmige Einbuchtung unter den Zentren, Aufwölbung unter den Rahmen. Die Zentren waren dermaßen durchtränkt, daß bei jedem Spatenstich das entstehende Loch sich sofort mit Wasser und Erdbrei füllte.

\section{Fließerdezungen}

\section{Girlanden}

\section{Deformierte Steinringe}

\section{Steinringe (Fig. 13, a-d)}

Ein stark überwachsenes Netz von mehr oder weniger gut ausgebildeten Wülsten bedeckt in unregelmäßigen Abständen eine ziemlich trockene Verflachung. Einzelne Ringe stoßen aneinander, andere sind durch Gräben - teilweise oder ganz mit Steinen ausgefüllt - getrennt, in denen stehendes Wasser sichtbar ist. Gräbt man nach der Oberfläche der Tjäle, so findet man diese in der auffallend großen Tiefe von $70 \mathrm{~cm}$ (vergleiche Form 8 von Profil 1!). Die Zentren zeigen trotz des benachbarten Wassers keine breiartige Konsistenz. Die Wülste bestehen aus Humus und starkem Wurzelwerk, das Feinerde und Steinchen festhält.

4 Möglichkeiten des Aneinanderstoßens benachbarter Ringe können festgestellt werden :

a) 2 benachbarte Wülste berühren sich direkt. Trotzdem kann man die beiden Massen deutlich auseinanderhalten.

b) ein Graben von 50-100 cm Breite, teilweise - v. a. randlich - mit Steinen ausgefüllt, trennt 2 Nachbarn. Einzelne Pflanzen haben sich in der steinfreien Grabenmitte angesiedelt.

c und d) in zunehmendem Maße erfüllt ein «falscher» Steinrahmen, beidseits von den bewachsenen Wülsten begleitet, den Graben. Selten allerdings ist er zum Kreis geschlossen. Auch gröbere Trümmer haben sich eingefunden. Die Bewachsung greift von den Wülsten her stellenweise auf die Steinfüllung über.
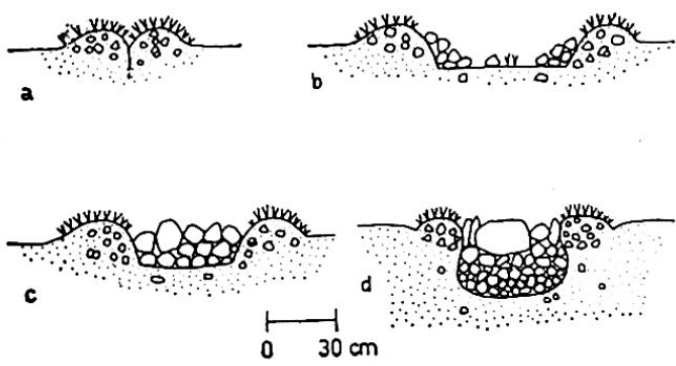

Fig. 13 Profile zwischen je 2 Steinringen. 


\section{Miniaturformen}

Der feuchte Hang über einem kleinen Strandsee ist durch kleine Formen gemustert, die entlang dem Meer bis zu Profil 2 und darüber hinaus verfolgt werden können.

\section{Fließerdezungen}

Große Zungen überkleistern stellenweise die Schichtköpfe. Ihr Rücken ist durch schmälere Zungen gegliedert, die ihrerseits wieder Girlanden tragen. Eine Steinumrandung fehlt den Zungen, dagegen ist die Stirn stark überwachsen.

\section{Girlanden}

Die nördlichste Wallmoräne weist in diesem Profil eine größere Hangneigung als im Profil 2 auf. In der flacheren Partie sind die Girlanden klassisch ausgebildet (vgl. Lit. 3, Abb. 29 und Fig. 3a S. 250). Mit zunehmender Versteilung aber verändern sich die Formen: die Vegetationsränder reichen rückwärts nicht mehr bis zu den höher gelegenen Girlandenstirnen (vgl. Lit. 3, Abb. 30 und Fig. 3b). Demzufolge ordnet sich die Vegetation eher bandartig quer zum Hang. Die Bewachsungsverhältnisse entsprechen denen des Nationalparks: Pionierpflanzen besiedeln hauptsächlich die Stirn, die Rücken bleiben i. a. kahl. Dafür zeigen letztere eine lebhafte Musterung: Rißpolygone mit und ohne Steinchen (= Zellenboden), Steinnetze mit schwach aufgewölbten Feinerdezentren, auf stärker geneigten Rückenflächen Erd- und Steinstreifen. Aus diesem Grunde ist der nördlichste Abschnitt dieses Profils reicher an Miniaturformen, als die Kartierung zeigt.

\section{Riesige Fließerdezungen}

Wie auf Fop da Buffalora im Nationalpark (Lit.3, Abb. 37) fließt die ganze Schuttbedeckung von der Moräne herunter. Solange die Neigung ca. $20^{\circ}$ beträgt, lassen sich noch kaum Fließstrukturen erkennen, während sich im flacheren untern Abschnitt (Neigung ca. $10^{\circ}$ ) mächtige Zungen ablösen, die bis zum Bach vorstoßen. Sie sind gleich ausgebildet wie die Zungen auf der andern Seite der Kuppe, nur zeigen ihre Rücken eine dichtere Bewachsung.

\section{Feinerdeinseln}

\section{Girlanden}

Die geringste Zunahme der Hangneigung genügt, um die Feinerdeinseln in Girlanden zu verwandeln.

\section{Steinpolygone}

Auf dem der aktiven Moräne unmittelbar vorgelagerten Schotterboden treten einzelne Polygone auf, die bei zunehmender Hangneigung eine deutliche Deformation zeigen. Im Verhältnis zum Durchmesser sind die Rahmen auffallend breit. Eckige, grobe Steine stehen kantengestellt und tangential zum Umriß in einer flachen, breit-U-förmigen Rinne. Das Zentrum ist breiig-weich, die Oberfläche zeigt eine krümelige Struktur; gelegentlich kommen auch Rißpolygone darauf vor. Eine der Formen scheint ein frühes genetisches Stadium zu vertreten: das Zentrum ist noch nicht völlig steinfrei, zeigt aber eine klare Sortierung - Zunahme der Korngröße vom Mittelpunkt nach außen - und beginnende Kantenstellung. - Auch im Rahmeninnern sind die Steine kantengestellt, während eine Sortierung nach der Steingröße nicht feststellbar ist. 
Unter Tjäle verstehe ich den gefrorenen Boden, über dem der sommerliche Auftauboden liegt. In Spitzbergen handelt es sich dabei um perenne Tjäle - ewige Gefrornis - oder Dauerfrostboden.

Die Tjäleoberfläche ist, in allen gegrabenen Profilen, ganz besonders unter Steinrahmen durch starke Eisanreicherung gekennzeichnet. Das Eis kann sehr hart sein, eingefrorene Steine können nur schwer losgebrochen werden.

Gesamthaft betrachtet bildet die Tjäleoberfläche unter Feinerdesäulen von Ringen eine flache, uhrglasförmige Schale, außer bei den sohlenständigen Polygonen (Fig. 10). Feinerde- und Tjäleoberfläche sind gegensinnig gekrümmt. Dies gilt auch für stạrk deformierte Steinringe und die Flächen zwischen Steinstreifen. Von sämtlichen vermessenen und skizzierten Steinstreifen (z. B. Fig. 8) sind die in Fig. 4 dargestellten die einzigen mit Wasserführung und einer kastenförmigen Eintiefung der Tjäle unter der Steinfüllung (vermutlich als Folge von Wärmetransport durch Wasser). Fig. 5 veranschaulicht einen Zustand, bei dem der Tauprozeß etwas weiter fortgeschritten ist als bei den andern Steinwülsten, wobei kein zirkulierendes Wasser beobachtet wurde.

\section{Auftautiefe und Exposition:}

(Moränenwall, Profil 1, 1. 7. 1956, schneefrei, ohne Berücksichtigung der Verhältnisse unter Steinrahmen)

NNE Exposition (Mittel aus. je 5 Messungen)

SSW Exposition

Raum der Form $130 \mathrm{~cm}$

$212 \mathrm{~cm}$

$4 \quad 35 \mathrm{~cm}$

Mittel : $\underline{24 \mathrm{~cm}}$

dem Gletscher zuge-

kehrter Moränenhang: $28 \mathrm{~cm}$

Die größten Auftautiefen bei Strukturbodenformen im Raume der Profile $\mathrm{I}-3$ betragen: sohlenständige Steinpolygone Steinringe

Profil $2 / 4$ $2 / 11$

$1 / 8$

Fig. 10

Fig. 13

Fig. 6

$40 \mathrm{~cm}$

Steinringe

Diese Formen besitzen keinen Steinwulst, dagegen einen Steinrahmen, der gegenüber dem Feinerdezentrum vertieft ist.

Auftautiefe und Schneeflecken:

(horizontale Fläche, Blomstrandbucht, 30.6.1956)

Distanz vom
Schneefleck
$0 \mathrm{~cm}$
$30 \mathrm{~cm}$
$50 \mathrm{~cm}$
$100 \mathrm{~cm}$
$150 \mathrm{~cm}$
$200 \mathrm{~cm}$
$300 \mathrm{~cm}$
$400 \mathrm{~cm}$
$500 \mathrm{~cm}$

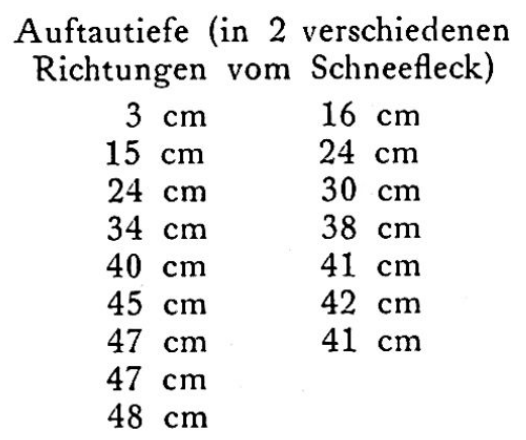

DIE AMUNDSENSTEINRINGE (FIG. 14, ABB. 2)

Unterhalb des Amundsengedenksteins, se $\mathrm{Ny}$ Alesund, dehnt sich eine schwach gegen den Fjord geneigte Fläche aus. Sie ist durch weitgehende Überwachsung und 
durch ein Netz von dicken Steinwulstringen gekennzeichnet, deren regelmäßige Ausbildung sogleich in die Augen sticht. Auffallend ist auch die Größe der Formen: die gegenüber den Steinwülsten schwach vertieften, meist planen oder nur-leicht gewölbten Zentren messen selten weniger als $2 \mathrm{~m}$ im Durchmesser, die Wülste können bis $1 \mathrm{~m}$ breit sein. Die Flächen - «Gräben»-zwischen den Ringen liegen etwas tiefer als die Ringzentren. Die Vegetation ist am Innenrand der Wülste stärker entwickelt als aussen (ähnlich wie in Fig. 5), die Steinwülste sind oben nackt. Die Tjäle wurde in $70 \mathrm{~cm}$ Tiefe noch nicht erreicht, die ganze Fläche war trocken, erst im Steinbett, in über $70 \mathrm{~cm}$ Tiefe, trat Wasser auf.

Betrachtet man die gegenseitige Lage der Formen, so lassen sich 2 Fälle auseinanderhalten:

a) Die Steinwülste benachbarter Formen berühren sich nicht. Jedes Feinerdezentrum ist von 2 Wülsten umgeben, von denen der innere, gut überwachsen, aus Steinchen und Feinerde mit Wurzeln besteht. Der äußere Ring dagegen, der eigentliche Steinwulst, ist nackt und feinerdefrei. Unter ihm wird eine dünne, braune Schicht mit abgestorbenem Pflanzenmaterial - besonders bis $3 \mathrm{~cm}$ lange Würzelchen - sichtbar.

b) Die beiden benachbarten Steinwülste berühren sich und gehen ineinander über (Fig. 14). Die «Humusschicht» konnte unter dem gemeinsamen Steinwulst wiederum nachgewiesen werden. Räumt man die lose gelagerten Kiesmassen unter dem Steinwulst weg, so sackt dieser nicht sogleich nach, da die Humusschicht ihn hält. Mit zunehmender Tiefe wird der Anteil an Feinerde in der Kiesmasse größer.

Fig. 14 Profil durch den Steinwulst zweier Amundsensteinringe. 1 dunkelbraune, humose Schicht. 2 gelbgraue, harte Masse. 3 gelbes, sandiges Material. 4 Steine und Würzelchen. 5 rötlichviolettes, sandiges Material. 6 Steine und Feinerde. 7 Steine.

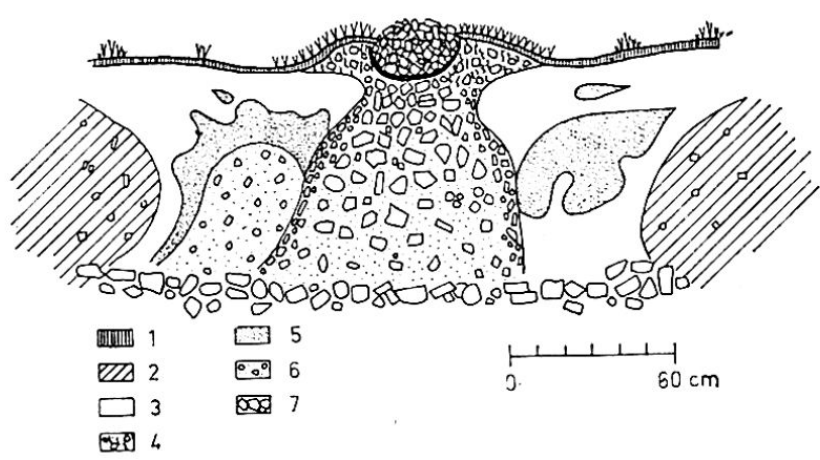

Um das Problem der praktisch kreisrunden Feinerdebeulen, die von Schnee, grobem Schutt oder Vegetation umgeben sind, näher zu beleuchten, wurden im Raume der Profile 1-3 einige Vertreter dieser Erscheinung aufgegraben.

Fig. 15, a) Diese Form ist von flach ausgebreiteter Vegetation umgeben, unter der ein Steinrahmen zum Vorschein kommt. Die steinarme Feinerdesäule hebt sich deutlich gegen anders gefärbte Feinerde unter dem Rahmen ab. Das lockere Steinbett mit ziemlich viel Feinerde ist unter dem Beulenzentrum aufgewölbt. Die Tjäle wurde nicht erreicht. - Dieser sicher vorübergehend inaktive Steinring liegt in nächster Nähe von absolut vegetationsfreien Strukturbodenformen.

Fig. 15, b) Diese Feinerdebeule ist auch durch einen Vegetationsring begrenzt, unter dem aber kein Steinrahmen liegt. Seine Stelle nimmt eine humos-sandige Schicht von $\pm 5 \mathrm{~cm}$ Mächtigkeit ein. Die «Feinerdesäule» ist komplizierter begrenzt als im ersten Fall, ihre Untergrenze ist in Taschen gegliedert. Das Steinbett ist gleich wie bei der Form von Fig. 15 a. Zwischen der «Feinerdesäule» und dem Steinbett aber liegt eine mit Steinchen durchsetzte zähe, lehmige Masse. - Oberflächlich sieht die Fein- 
erdebeule gleich aus wie jene von Fig. 9 (Profil 1/20), Unterschiede ergeben sich erst beim Graben: kein Eisnapf (der auch bei Profil 1/12 fehlt), hingegen werden ähnliche Strukturen sichtbar wie in Fig. 9 links.

Fig. 15, c) Die Feinerdesäule geht seitlich in gleitendem Übergang in eine von Steinchen durchsetzte Zone über, die bis auf das Steinbett hinunter reicht. Dieses ist in seinem Zentrum ebenfalls deutlich aufgewölbt.

Fig. 15, d) Ganz nahe bei der zuletzt beschriebenen Form liegt ein Steinring, dessen Steinbett aber praktisch horizontal durchzieht.

So zeigen diese Beispiele deutlich, mit welchen Schwierigkeiten man sich beim Kartieren auseinanderzusetzen hat. Ein weiterer Fall einer Feinerdeinsel mit schwach aufgewölbtem Zentrum wird im Abschnitt über Sverdruphamaren beschrieben: ohne daß sich ein Steinring oder gar ein -wulst bildet, sind die Steinplatten der Umgebung an der Grenze der Feinerde kantengestellt und tangential zu ihr angeordnet.

\section{DIE RIESENSTREIFEN VON BRAND'ALPYNTEN (FIG. 16)}

Zwischen dem Meer und dem westlichsten Bach von Fig. 17 (n Pt. 688) erhebt sich ein Sporn mit drei steilen Hängen und einer praktisch horizontalen Oberfläche. Diese überragt den Meeresspiegel um $\pm 20 \mathrm{~m}$. Auf dem Sporn wurden drei eigenartige, schwach gewölbte Streifen beobachtet. Diese sind im Gegensatz zur trockenen Umgebung feucht und beidseits von dunklen Bändern begleitet. Zwei dieser Streifen verlaufen parallel zueinander und überqueren die Spornoberfläche in ihrer ganzen Breite $(6-8 \mathrm{~m})$. Der eine mißt $85 \mathrm{~cm}$ in der Breite, der andere $150 \mathrm{~cm}$. Der dritte Streifen ist $40 \mathrm{~cm}$ breit und zweigt rechtwinklig vom östlicher gelegenen sporneinwärts ab. Zunächst verläuft er einige $m$ geradlinig und biegt dann zur bachwärts gelegenen Spornkante um.

Die Oberfläche der Streifen ist im Gegensatz zur Umgebung durch Rißpolygone gegliedert. Fig. 16 zeigt ein Querprofil durch einen solchen Streifen: Über der Tjäle, die unter der Aufwölbung schwach eingebuchtet ist, folgen Feinerdelinsen und -schichten, die durch starke Farbunterschiede sich gut auseinanderhalten lassen. Auffallend ist eine gewisse Symmetrie der mehr oberflächlichen z. T. taschenartig gelappten Komplexe in Bezug auf die zentrale Aufwölbung. Selbst Partien außerhalb der begleitenden dunklen Bänder ordnen sich im gleichen Sinne. Ein ausgeprägtes, graues und gelbes Band zieht ohne Störung horizontal durch die Form und zerlegt diese in einen basalen und einen oberflächlichen Teil. Ersterer konnte im Bereiche der hellgrauen sandigen Linsen leicht ausgeräumt werden. Die beiden dunklen randlichen Bänder setzen sich in die Tiefe keil- bis linsenförmig fort.

Diese Form wurde sonst nirgends gefunden, eine Deutung ist anhand so weniger Daten problematisch.

\section{BLOMSTRANDBUCHT (FIG. 17 OBEN RECHTS)}

In rezenter Zeit ist der Blomstrandbreen beträchtlich zurückgeschmolzen. Die ihm vorgelagerte klassische Moränen- und Sanderfläche wird durch einen Meeresarm von der heutigen Gletscherfront getrennt.

Fig. 15 Feinerdebeulen und Steinring (d). 1 Steinbett (Feinerde und Steine). 2 Steine ohne Feinerde. 3 humos-sandige Feinerde. 4 gelbbraune, sandige, fast steinfreie Feinerde. 5 graue, lehmige Masse. 
a

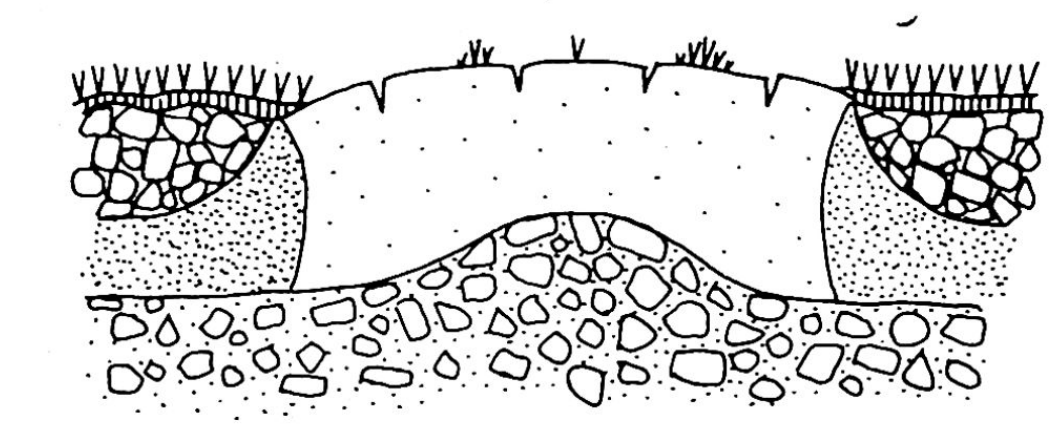

$b$
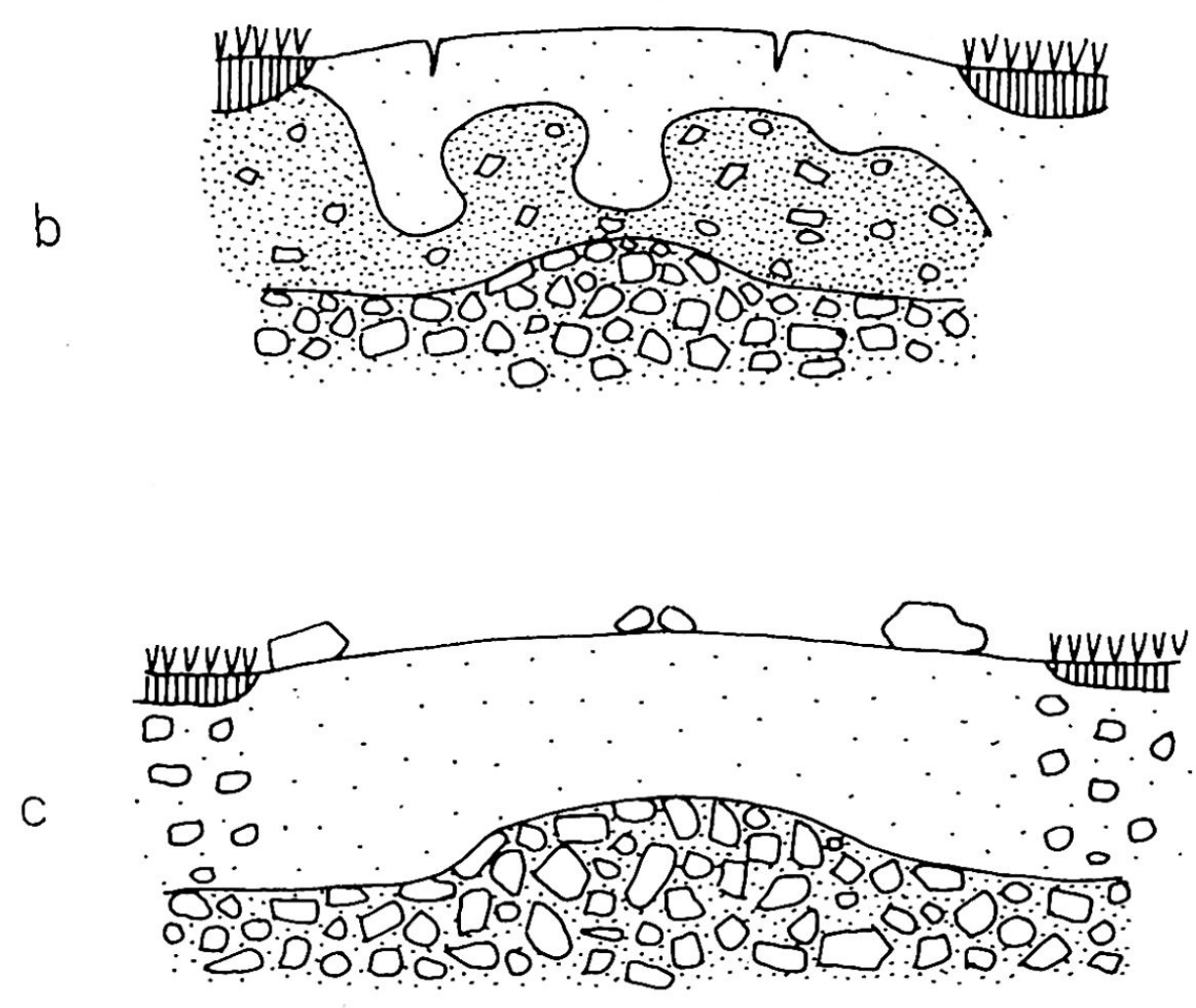

$d$
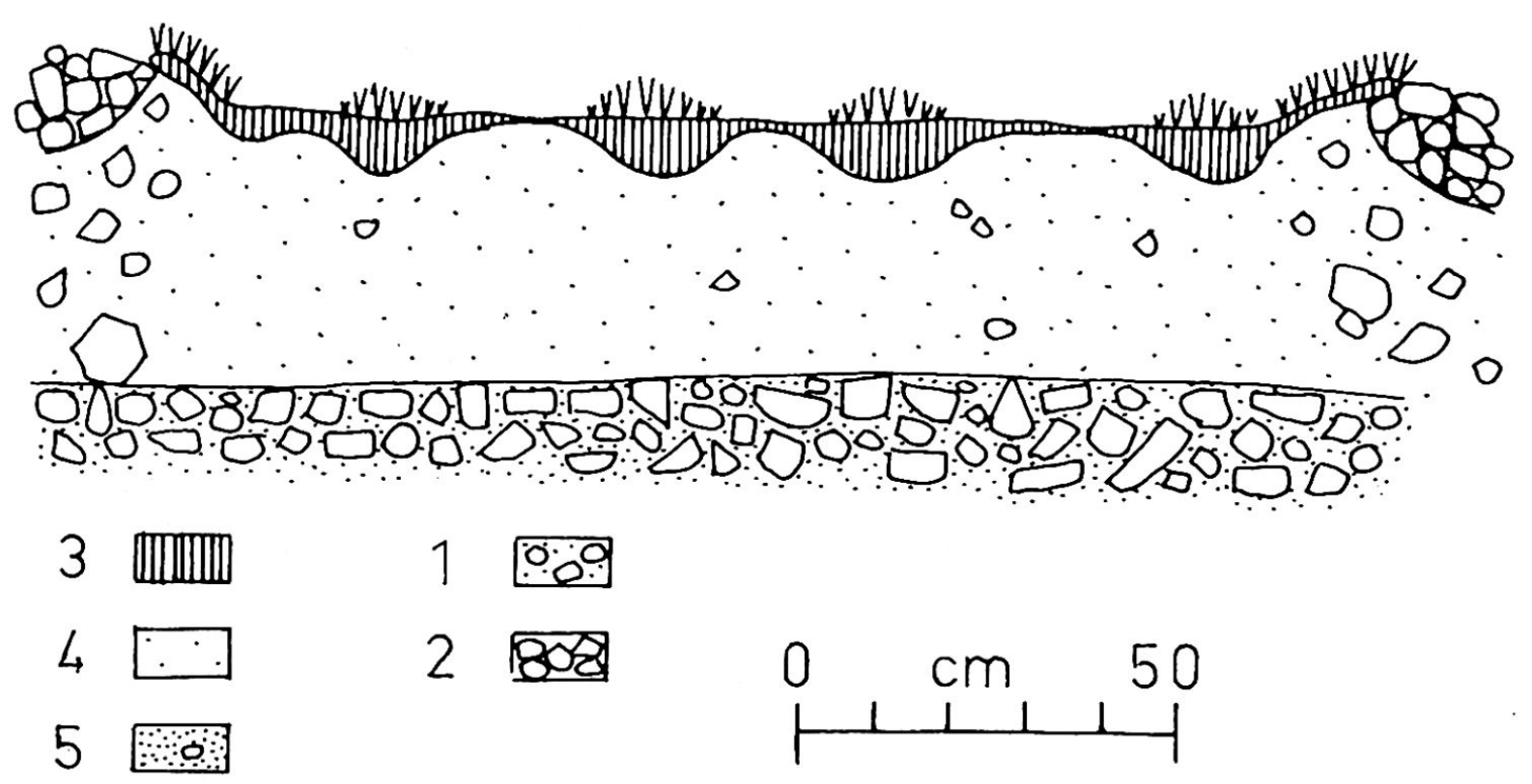


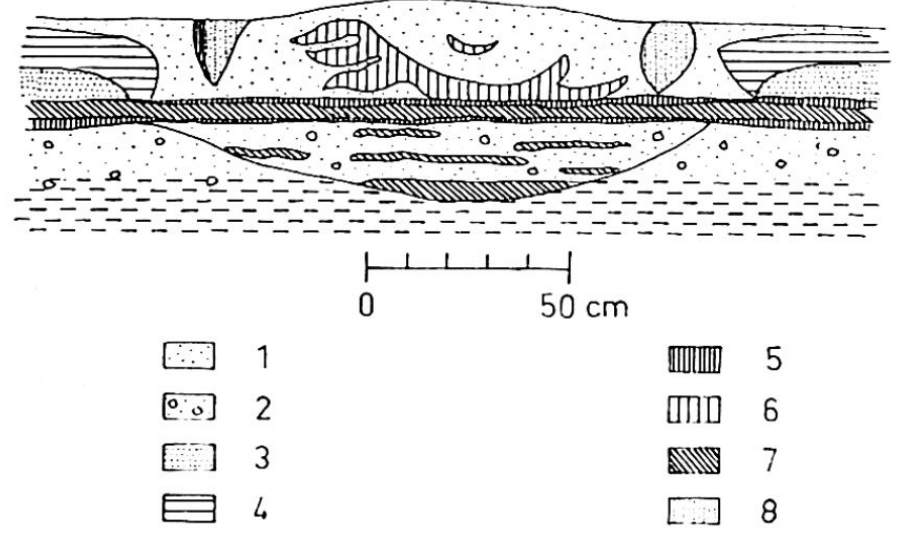

Fig. 16 Riesenstreifen von Brandalpynten. 1 gelbbraune Feinerde. 2 gelbbraune Feinerde mit Steinchen. 3 gelblich-grauer, schwach geschichteter Sand. 4 dunkelbrauner, blättriger Torf mit Sandeinlagen. 5 dunkelgelbe Feinerdebänder. 6 dunkler, rotbrauner Sand mit Würzelchen. 7 hellgrauer, feiner Sand. 8 lockeres, sandiges, graues Material.

Dieses Gletschervorland kann in mehrere Abschnitte aufgeteilt werden. Jede dieser Einheiten zeigt einen eigenen Formenschatz.

1. Die Strandfläche innerhalb (in Fig. 17 s Pt. 465) der Endmoräne besteht aus Schlick, Sand und Schottern und ist - abgesehen von einem bewegten Kleinrelief praktisch horizontal. Gestrandete Eisberge liegen nahe der Wasserkante, gelegentlich von Sand und Schlamm, bis zur Unkenntlichkeit, bedeckt. Strukturböden findet man keine, dagegen stößt man auf einige unvermittelt sich aus der flachen Umgebung erhebende Hügel mit kreisrundem Grundriß, kegelförmiger Gestalt und einem abgeflachten bis eingedrückten Gipfel. Ihre Höhe beträgt ca. $3 \mathrm{~m}$; die Oberfläche ist, genau wie die Umgebung, von Schutt übersät, der starke Frostsprengung zeigt. Das Innere aber besteht aus weicher, stark durchfeuchteter Feinerde. Auf dem Basisniveau konnte bis $1 \mathrm{~m}$ gegen das Zentrum weder Ëis noch gefrorener Boden festgestellt werden.

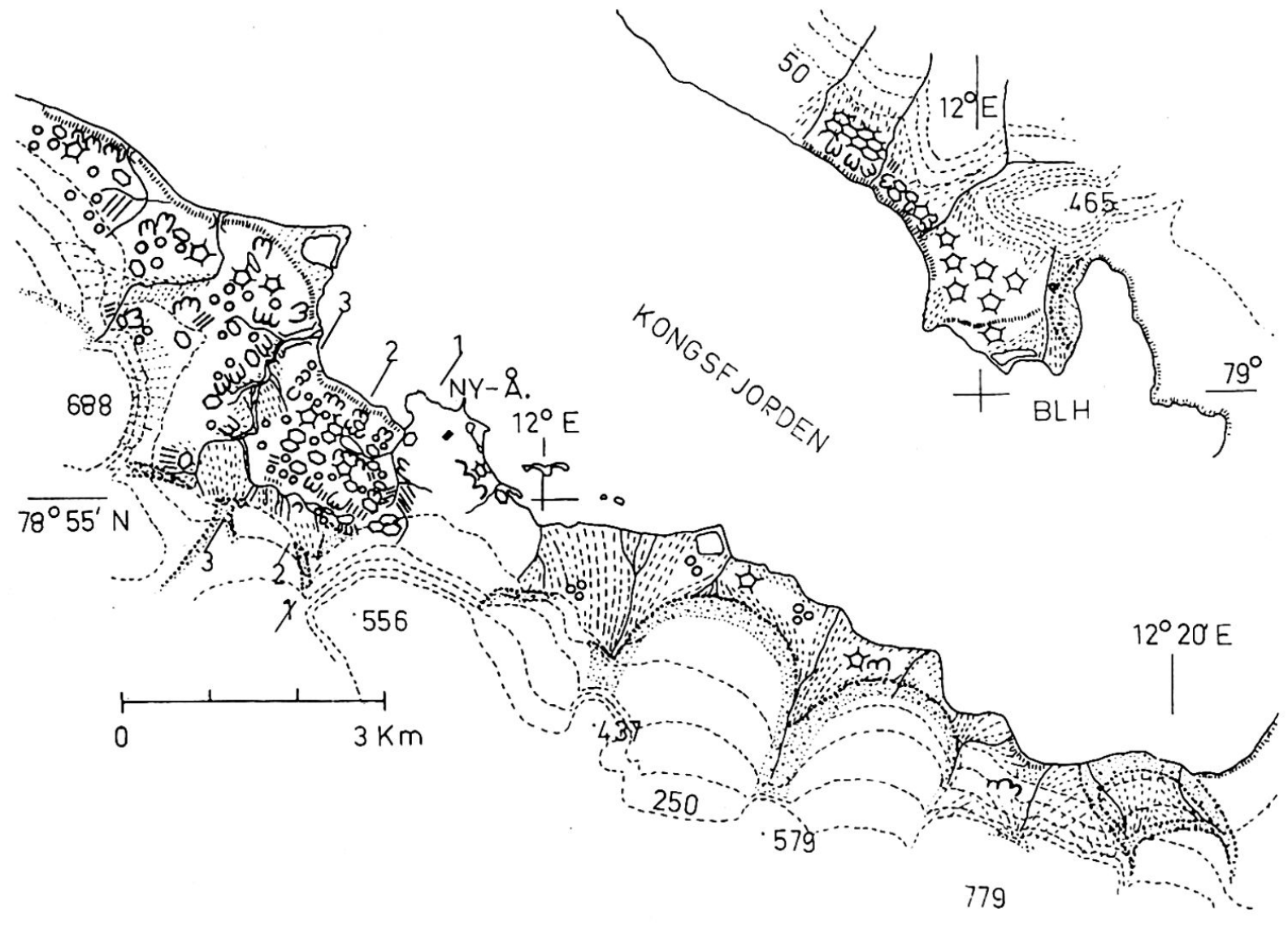

Fig. 17 Karte Raum Ny Alesund (unten) und Blomstrandhamna (oben). Aequidistanz $50 \mathrm{~m}$. (Ny-A = Ny-Alesund). Punktiert: jüngste Moränenkränze; fächerartig gestrichelt: Schwemmfächer; weiße Flächen außerhalb der Moränen: Tundra mit dürftiger Vegetation, südl. Ny Alesund Bergwerkareal. 
2. Der Moränenkranz ist stark fluviatil zerschnitten. Sein unverfestigter Schutt ist auffallend bunt in Größe und Material. Wie bei diesem Zustand der Moräne zu erwarten ist, findet man auch hier keine Strukturböden; dafür besteht alles aus aktiver Fließerde, unter der in Spatentiefe der gefrorene Boden folgt. Fließerdezungen verschiedenster Größe überkleistern in Scharen die Abhänge, haben stellenweise sogar die restlichen Schneeflecken überfahren. Ihre Rücken zeigen klare Strömungswülste.

Wie Miniaturvulkane haben einige Beulen von Feinerde (Durchmesser $\pm 1 \mathrm{~m}$ ) die wenig mächtigen Schneeflecken durchbrochen. Die niedrigen Beulen bestehen aus zäher, aber breiartig weicher Feinerde. Das Relief der feuchten Oberfläche erinnert an einen Blumenkohl. Die Aufwölbungen sind rund herum von einer $3-5 \mathrm{~cm}$ dicken, körnigen Schneeschicht begleitet, die sich leicht wegräumen läßt. Darunter folgt harter, verfirnter Schnee, der sich unter den Hügelrand hineinzieht, aber bald einem hart gefrorenen Boden Platz macht. Dieser reicht nicht bis unter das Zentrum der Beule, denn auch in Spatentiefe stieß man dort auf keinerlei Widerstand.

3. Außerhalb der Moräne; praktisch auf Meereshöhe, folgt eine Sand- und Schotterfläche, von ungezählten, stets wechselnden Wasserarmen durchfurcht. Wo sie aus Kies besteht, sinkt man sofort schuhtief ein. Flache Miniaturbeulen von $15-25 \mathrm{~cm}$ Durchmesser durchbrechen die Schuttspreu. Frostsprengung hat sehr viel Steine in kleine, eckige Trümmer zerlegt, die man bei flüchtiger Betrachtung für Steingärtchen halten könnte, besonders wenn die Trümmer anders gefärbt sind als ihre Umgebung.

4. Hangaufwärts wird die Schotterfläche abgelöst durch 2 scharf abgegrenzte Terrassen mit steilen Stirnen und schwach geneigten Rückenflächen, die fast durchgehend von Vegetation bedeckt und trocken sind. Sämtliche Polster sind auf der gleichen Seite bis zu den Wurzeln aufgescheuert: Windsichelrasen. Geradlinige Spalten teilen die Fläche in unregelmäßige Polygone auf, von denen später die Rede sein soll.

5. NW, fjordauswärts schließt sich eine eigentliche Tundrenfläche an den Strand an. Hier treten die im vorigen Abschnitt angedeuteten Tundrenpolygone besonders reich auf. Der Name wurde in Anlehnung an die von Bout aus Island (Lit. 1) beschriebenen Formen gewählt. Da sich Saxifraga oppositifolia nebst andern höheren Pflanzen besonders gerne in diesen Spalten ansiedelt, erweckt die Fläche den Eindruck eines unregelmäßigen Schottenmusters. Die Seitenzahl der Polygone ist sehr variabel, es gibt 4-10 seitige Formen. Wo mehrere Spalten zusammenstoßen, entstehen die verschiedensten Intersektionen (Fig. 18). FIG 18

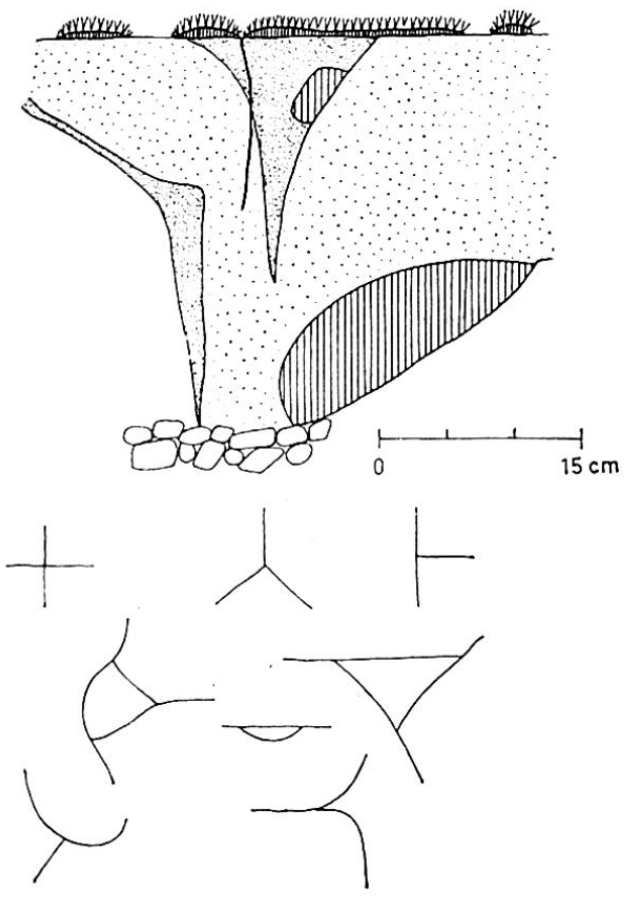

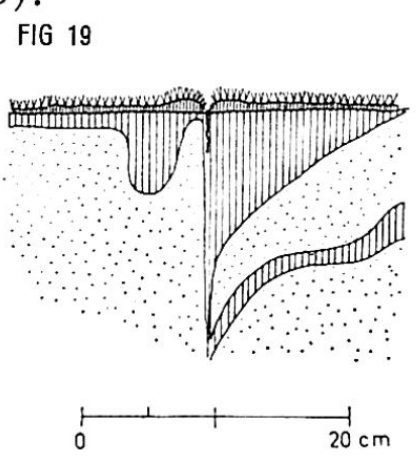

Fig. 18 Profil durch die Spaltenregion eines Tundrenpolygons und Möglichkeiten des Zusammenstoßens verschiedener Spalten.

Fig. 192 Profile durch die Spaltenregion von Tundrenpolygonen. Eng schraffiert: Wurzelschicht der lebenden Pflanzen; weit schraffiert: schwärzliche Erde, stellenweise fast kohlig; eng punktiert : körniger, gelblicher Sand; weit punktiert: braune, sandige Feinerde mit Wurzeln. dicker, senkrechter Strich: Riß. 
In ihren Ausmaßen sind die Formen mit den von Bout beschriebenen vergleichbar: Seitenlänge bis $20 \mathrm{~m}$. Die Profile der Spaltenregionen schwanken auf kleinstem Raum (Fig. 18 und 19). Manchmal trennt ein wirklicher Graben von mehreren $\mathrm{cm}$ Tiefe und Breite die seitlich ihn begleitenden flachen Wülste, an andern Orten verschmälert er sich zu einem bloßen Riß (Fig. 19). Aber bei allen aufgegrabenen Beispielen zieht sich ein auffallender Keil von schwarzbraunem, trockenem, erdig-sandigem Material bis in eine konstante Tiefe von $30 \mathrm{~cm}$. Seitlich werden diese Keile von mancherlei Taschen begleitet, die sich in Farbe und Beschaffenheit unterscheiden können. Die Risse sind 3-14 cm tief. Bis auf $40 \mathrm{~cm}$ hinunter konnte kein Eis festgestellt werden, noch tiefer folgte ein dicht gepacktes Steinbett.

Leider fehlen in der Arbeit von Bout Profilbeschreibungen.

Der Vegetationsbefund und die Trockenheit des Bodens könnten Hinweise dafür sein, daß diese Formen längst inaktiv geworden sind. Das Problem, wie das schwarzbraune, humose Material in die Tiefe gelangt ist und wie die verschiedenen Taschen entstanden, bleibt offen. Handelt es sich wohl um eine abgewandelte Form von Frostspaltenboden, wie er bei Troll (Lit. 9, S.639) aus Grönland und Spitzbergen beschrieben ist?

Wo die Tundrenfläche in einen sanften Abhang übergeht, löst sich die Vegetation zu Inseln auf, und dicht gescharte Erdstreifen von mehreren m Länge bedecken weite Flächen. Sie bewahren auf große Distanzen eine auffallende Konstanz der Beschaffenheit und der Dimensionen. Die aufgewölbten, krümligen Feinerdepartien, in denen kleine Steinchen (Durchmesser bis $2 \mathrm{~cm}$ ) regellos eingebettet liegen, sind ca. $2 \mathrm{~cm}$ breit und erheben sich $2-3 \mathrm{~cm}$ über eine flache, $5-6 \mathrm{~cm}$ breite Rinne. Die Streifen folgen streng jeder Änderung der Fallinie und umfließen jedes Hindernis dichter geschart.

6. Während im Innern der Bucht der Strand flach ist, erhebt sich fjordauswärts die Strandterrasse immer mehr über ein Kliff. Sie ist durch tief eingeschnittene Bäche gegliedert. Über ihr folgen schroffe Berghänge mit endlos nackten Schutthalden. Solange die Vegetation geschlossen ist, treten 'Tundrenpolygone auf; bei Auflösung derselben in Polster und einer zunehmenden Bedeckung des Bodens mit Schutt werden die Polygone durch Girlanden und Schuttzungen abgelöst. Erdstreifen und kleinere Steinringe gesellen sich dazu. Noch weiter fjordauswärts reicht die grobblockige Schuttdecke von den Berghängen bis weit in die Terrassenfläche hinaus. Alle Depressionen zwischen, quer zur Küste verlaufenden, anstehenden Rippen sind mit Steinnetzwerk verschiedenster Dimensionen erfüllt. Stellen mit wenig mächtiger Schuttbedeckung in höheren Partien zeigen vor allem Miniatursteinkreise, die denen aus unseren Alpen zum Verwechseln gleichen (minimaler Zentrumsdurchmesser $4 \mathrm{~cm}$ ). In nächster Nähe von ihnen, auf mächtigeren Böden, liegen Steinwulstringe, deren Zentren wieder durch Miniaturformen aufgegliedert sein können. Bei zunehmender Hangneigung gehen alle Formen in ein mehr oder weniger differenziertes Schuttfließen über.

\section{ADVENTFJORD AN DER WESTKÜSTE SPITZBERGENS}

$$
78^{\circ} 15^{\prime} \mathrm{N}, 14 .-25.7 .1956
$$

In den Adventfjord mündet von $\mathrm{S}$ das Longyeardalen. Oberhalb seiner linken - westlichen - Flanke breitet sich eine weite Fläche - Sverdruphamaren - aus. Ihr Formenschatz ist in Fig. 20 festgehalten. Die Profillinie beginnt bei der Endmoräne des Nordenskjöldgletschers - Fig. 20 oben, rechts - und verläuft parallel zum Longyeardalen bis zum kleinen Hafen bei der Gouverneursiedlung - Fig. 20 unten, links. 
Das Plateau zeichnet sich durch eine auffallend geringe Reliefgliederung aus. In einer schwachen Depression - wo in Fig. 20 die Profillinie entzweigeschnitten ist : liegt die Wasserscheide zwischen einem Bach, der nach SE ins Longyeardalen fließt und einer Rinne, die durch das Blomsterdalen die Adventbay in nnw Richtung erreicht.

Dieses Plateau besteht aus 2 Einheiten: Im Gletschervorfeld, bis halbwegs zu den erwähnten Bächen, dominieren Feinerde und kleinere Steine. Diese Fläche ist erst kürzlich schneefrei geworden. Der feuchte Boden ist fleckenweise von auffallend geschlossener Vegetation bedeckt: Moospolster wie Schwämme mit Wasser vollgesogen, Gräser, Salix polaris, kleine Ranunculi. - Der größere Abschnitt des Plateaus dagegen ist von grobem, meist plattigem Schutt bedeckt. Feineres Material ist an der Oberfläche auf Polygonzentren beschränkt. Außer Flechten beobachtet man keine nennenswerte Vegetation.

Vor der Endmoräne, auf sehr feuchtem Boden mit weitgehend geschlossener Vegetation, lassen sich kleine, feuchte und aufgewölbte Feinerdeinseln mit netzartig aufgerissener Oberfläche beobachten. Stellenweise sind die Risse mit feinen Steinchen gefüllt.

Im Bereiche der Tundrenpolygone, die kleinere Dimensionen aufweisen als jene von Blomstrand, ist die Vegetation noch immer gut entwickelt. Die Oberfläche der Polygone zeigt Miniaturformen: Steinnetze und -streifen, Feinerdepflaster und -knospen. Bei den folgenden Steinpolygonen herrschen zwar noch die kleineren Korngrößen vor, die Vegetation dagegen tritt fast ganz zurück. Die Polygone sind unregelmäßig, weisen schmale, vertiefte Rahmen mit relativ kleinen Trümmern ohne Kantenstellung auf. Ihre Zentren sind leicht aufgewölbt, von einer Steinspreu und einigen Polsterpflanzen bedeckt.

Unmittelbar, ohne fließenden Übergang, wechselt der Schutt zu groben, plattigen Sar.dsteintrümmern, die stellenweise kantengestellt sind. Die Vegetation verschwindet ganz. Vereinzelt treten Steinringe auf, die sich stellenweise zu einem Netz verdichten. Ihre Zentren sind bei noch wenig deutlichen, vermutlich jüngeren Formen, weniger stark aufgewölbt als bei kräftig entwickelten. Im Steinrahmen erkennt man eine deutliche Zunahme der Korngröße nach außen. Jüngeren Formen fehlt eine eigentliche Rahmenbildung, nicht aber Kantenstellung an der Peripherie des Feinerdezentrums. Diese Formen sind durch auffallende Farbunterschiede der Steine weithin sichtbar: Die Rahmenpartien sind ockergelb bis rostbraun, die zentraleren dunkelolivgrün. Gräbt man in den Feinerdezentren nach, so kommen olivgrüne Steine zum Vorschein; zerschlägt man eine rostbraune Platte, so ist die frische Bruchfläche auch olivgrün mit einer deutlichen gelben bis rostbraunen Rinde. Letztere scheint nur als Verwiterungsprodukt erklärbar zu sein, da es sich bei allen Steinen um den gleichen Sandstein handelt. Aus dieser Beobachtung kann man den Schluß ziehen, daß die zentraler
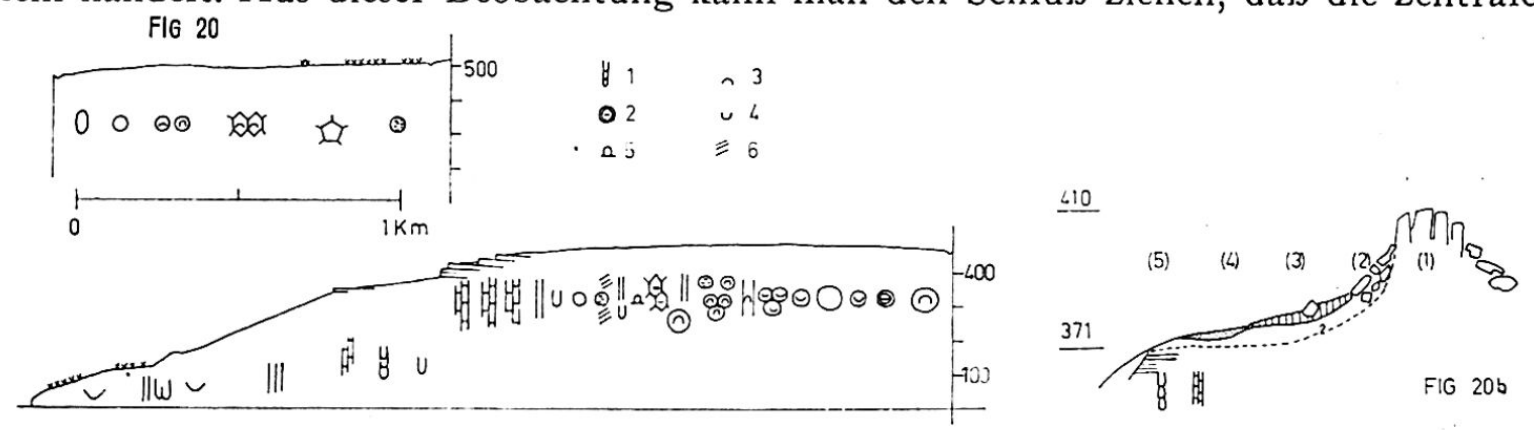

Fig. 20 Profil vom Meer über Sverdruphamaren zum Nordenskjöldgletscher. 1 girlandenartige Fließerdezungen, die durch Streifen von Vegetation voneinander getrennt sind; 2 Steinwulstringe (mit flachen Zentren); 3 aufgewölbte Feinerdezentren; 4 konkave, eingesenkte Feinerdezentren; 5 Feinerdehügel; 6 dachziegelartig gelagerte Steine. Fig. 20 b Profil vom Osthang des Longyeardalen. Senkrecht schraffiert: Schneeflecken; punktiert: aktive Fließerde. 
gelegenen Trümmer erst neulich aus dem Innern herausgearbeitet wurden, während die randlicheren Partien schon länger der Verwitterung ausgesetzt waren.

Gegen den Bach wird die Schuttdecke immer kompakter. Einzelne Steinringe heben sich als olivgrüne Inseln deutlich von der gelbroten Fläche ab. Mit zunehmender Hangneigung verschwinden die Feinerdezentren, ihre Stelle vertreten nur einzelne dunkle Feinerdeknospen. Um diese herum sind die Trümmer des künftigen Rahmens bereits kantengestellt und überragen ihre Umgebung leicht. Der Farbunterschied grün - gelb ist auch bei diesen Formen sichtbar.

Im groben Schutt am Bachbett hat es keine Strukturen, abgesehen von einer gewissen Einregelung der Trümmer. Auf sanft geneigter Fläche breiten sich auch einige Steinovale aus.

Auf der andern Bachseite folgen Riesensteinringe mit Durchmessern der Feinerdefläche bis zu $3 \mathrm{~m}$. Ihre Oberfläche ist hart, ausgetrocknet. Die kreisförmigen Zentren sind $20-30 \mathrm{~cm}$ über die Rahmen aufgewölbt und ragen weithin sichtbar über die steinige Umgebung hinaus. Im Innern der Kuppen fand sich kein Eis; dagegen sind auf und in ihnen regellos kleinere und größere Steine gelagert. In den Steinrahmen fällt eine weitgehende Rundung der etwa faustgroßen Steine auf, die einen deutlichen Gegensatz bilden zu den umliegenden groben, kantigen Sandsteinplatten. - Die Peripherie der Feinerdebuckel ist von einem kleinen Steinwall umgeben, der nach außen zu wachsen scheint und aus grünen, rundlichen Steinen besteht (Fig. 21 d). Bei einigen Vertretern kann beobachtet werden, wie dieser Steinwall auf die umgebende Schuttdecke abgleitet, wo er wulstartig gestaut wird (Fig. 21 e). Die Steine der Umgebung werden dabei etwas überschoben, sodaß 2 verschiedene Steinmassen aufeinander zu liegenkommen, zwischen denen - wenn vorher vorhanden - Moospolster eingebettet sind (Fig. $21 \mathrm{f}$ ). - Diese Riesensteinringe bilden ein weitmaschiges Netz. Breite, flache Schuttbänder aus rostroten Trümmern, manchmal von Moos- und Flechtenpolstern überwachsen, trennen die einzelnen Kuppen.

Meerwärts werden die Wülste immer ausgeprägter, sodaß man von richtigen Steinwulstringen sprechen kann (Fig. $21 \mathrm{k}$ ). Die Zentren sind flach, haben Durchmesser von ca. $2 \mathrm{~m}$, die Rahmen sind $30-50 \mathrm{~cm}$ breit und überragen die Zentren um einige $\mathrm{cm}$.

Durch eine quer zum Profil verlaufende leichte Depression zieht sich ein auffallendes Band von Grobschutt. Darin befinden sich einige vereinzelte Steinringe mit flachen, gegenüber der Umgebung etwas vertieften Zentren und deutlichen Rahmen aus kantengestellten, groben Trümmern. Von Weitem erinnern die Formen an kleine Dolinen. - Nach dem Grobschuttband treten wieder Riesensteinringe auf.

Einzelne Steinringe mit wiederum vertieften Zentren liegen ziemlich weit auseinander. Um die Zentren ordnen sich große, kantengestellte Sandsteinplatten, während die Umgebung aus einer dichten Packung von nicht besonders kantigen, meist faustgroßen Steinen besteht (Abb.3). In der Folge verschwindet der Unterschied zwischen grobem Rahmenmaterial und kleinerer Korngröße der Umgebung zeitweise ganz, indem die plattigen Trümmer mehr und mehr durch nuß-bis faustgroße Steine ersetzt sind. Die Form selber bleibt unverändert. Noch weiter vom Gletscher weg verringern sich die Abstände zwischen den einzelnen Formen, sie bauen ein Netz auf.

Mit dem Einsetzen einer schwachen Neigung beginnt sogleich die Deformation der runden Formen zu breiten, etwas unregelmäßig geformten Steinstreifen mit oft gewundenem Verlauf. Ihre Breite beträgt $\pm 1 \mathrm{~m}$, ihre Länge gegen $10 \mathrm{~m}$. Sie werden getrennt durch 2-3 m breite, leicht aufgewölbte Feinerdestreifen, die offensichtlich den Feinerdezentren der Kreisformen entsprechen. Auf ihrer Oberfläche hat sich zwischen einer lückenhaften Gesteinsspreu etwas Vegetation angesiedelt. Sobald die Hangneigung wieder abnimmt, gehen die Steinstreifen wieder in Steinringe mit gewölbten Zentren über. Der Farbunterschied olivgrün - ockergelb ist wieder auffallend. 


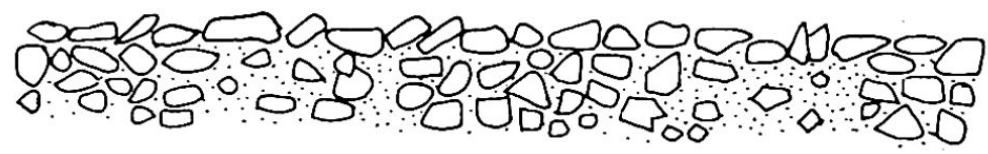

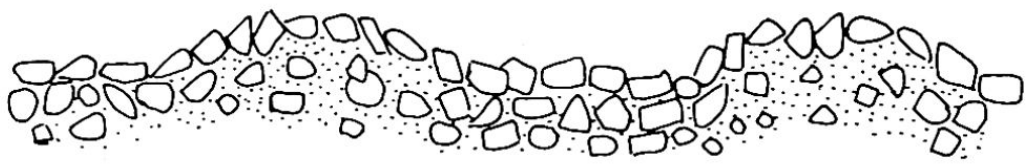

b

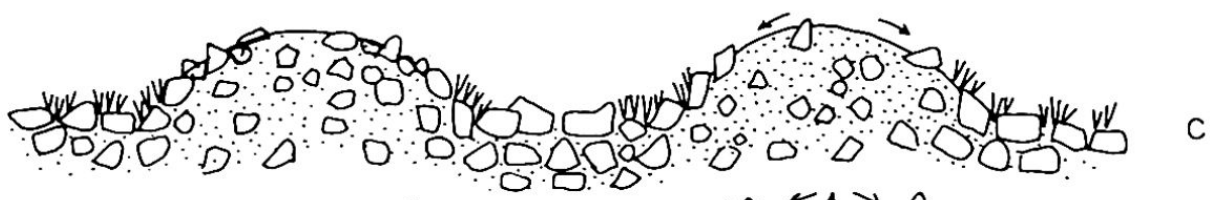

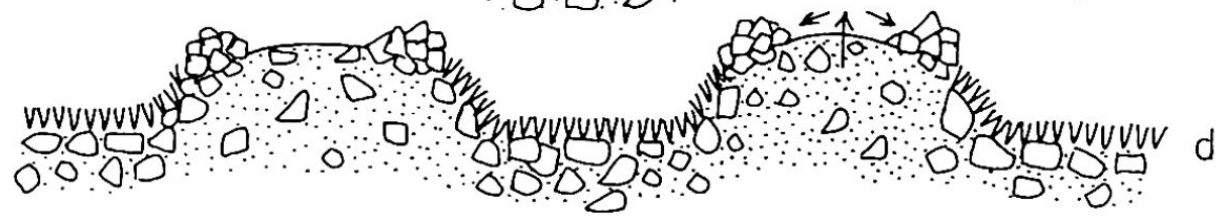

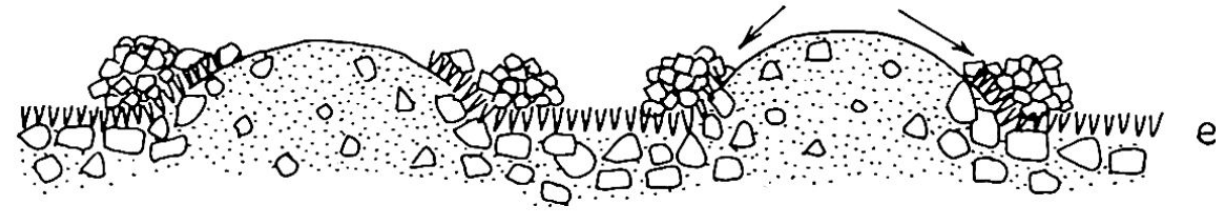

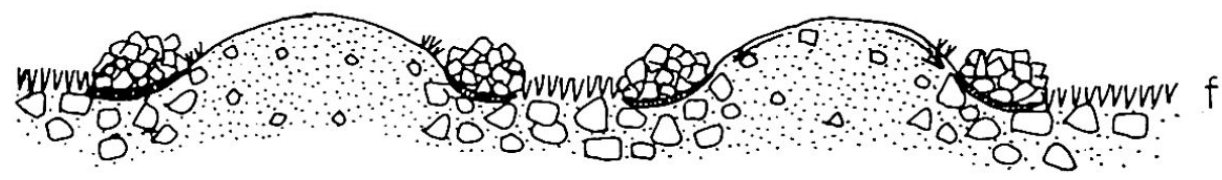

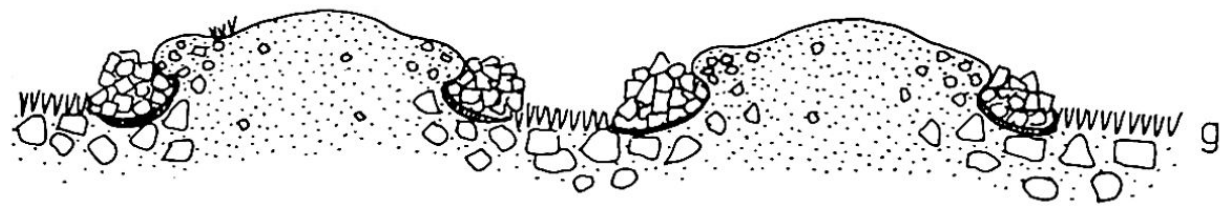
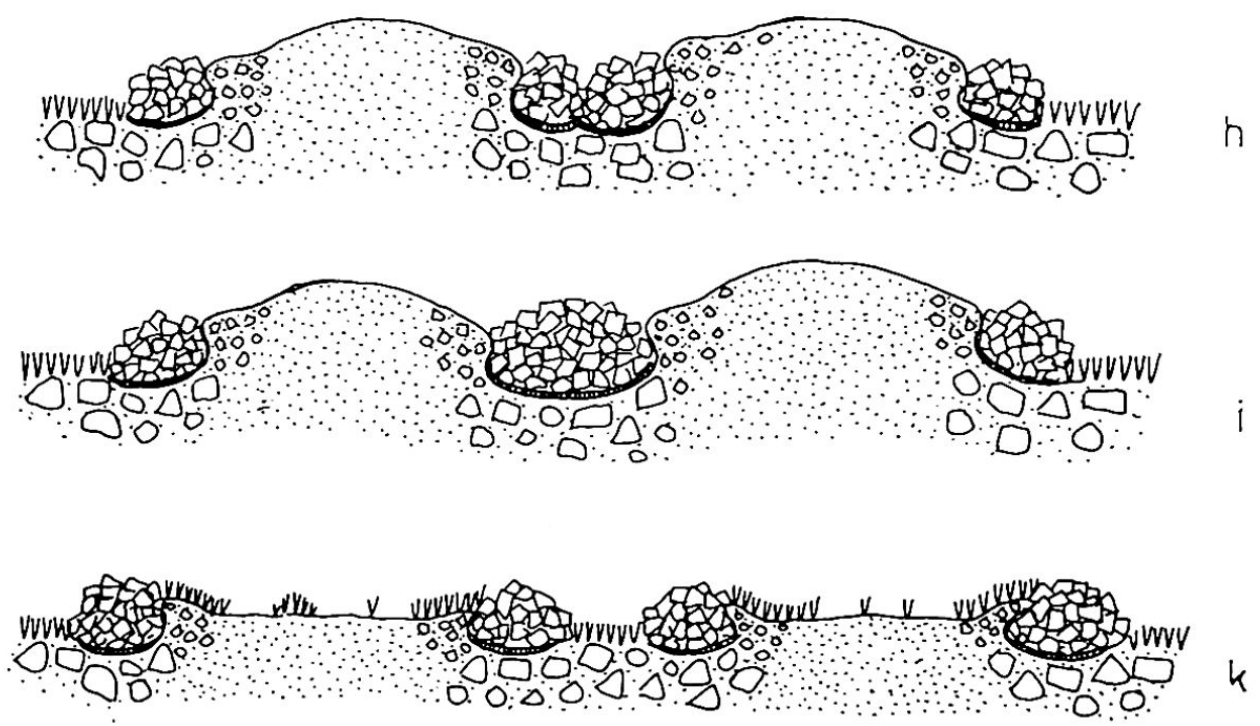

Fig. 21 Entwicklungsreihe der Steinwulstringe $(a-k)$ 
Zwischen plattigen Trümmern treten Feinerdeinseln auf. Sie werden von kantengestellten Steinen umsäumt, die aber nicht den Eindruck eines Steinrahmens erwecken. Eine erneute Hangversteilung bewirkt wiederum Deformation, es bilden sich Steinrinnen, die feinerdefrei sind. Auf vereinzelte Riesensteinringe folgt ein Steinpolygonnetz mit schmalen, versenkten Rahmen und flachen Zentren, die den Rahmen wenig überragen.

Feinerdehügel von $\pm 1 \mathrm{~m}$ Durchmesser werden von sehr schmalen Steinbändern umsäumt. In ihrer Nähe liegt breiartige Fließerde, in der man schuhtief einsinkt. Sie ist von schmalen Steinstreifen durchzogen, die an einigen Stellen durch gewundenen Lauf auffallen. Hie und da treffen sich 2 unter spitzem Winkel.

In einer quer zum Profil angeordneten Depression stellt sich sehr grober, kantiger Schutt ein, dessen Trümmer sich dachziegelartig überdecken. Stellenweise liegt Schnee zwischen den Steinplatten.

\section{DER HANG}

Beim Einsetzen der Hangneigung treten zunächst Steinzungen, dann Steinstreifen auf. Die Hangkrone ist durch Schichtköpfe charakterisiert. Die wenig mächtige Bedeckung der Schichtplatten - aus Feinerde und Steinen - trägt Pflasterboden. In Nischen lagern Schneeflecken, an deren Basis Schuttzungen von der Größe wohlentwickelter Girlanden zu beobachten sind. Wo die Hangneigung etwas abnimmt, schließen meerwärts an sie breite, flache Fließerdestreifen aus viel Feinerde und oberflächlicher Steinspreu an, die durch Vegetationsstreifen voneinander getrennt sind.

Je mehr man sich der untersten sichtbaren Schichtplatte nähert, desto «flüssiger» wird der Boden, bis knapp über dem Anstehenden harter Pflasterboden auftritt.

Der unterste Schichtkopf liefert viel Grobschutt, der sich hangabwärts zu 1-1,6 m breiten Steinstreifen - die den Eindruck von Steinrinnen erwecken - ordnet. Die Steine sind kantengestellt. Diese Formen erinnern an Streifenmuster von Kleinfimber (Lit. 6, Abb. 19). Sie bewirken eine unruhige Musterung, die Abstände zwischen den einzelnen Streifen variieren. In einigen fließt Wasser. Einige Girlanden treten in tieferer Lage an Stellen auf, wo mehr Feinerde zur Verfügung steht.

Dann folgen auf stärker geneigtem Hang Fließerdemassen mit Steinzungen. Die größten Steine bilden die Stirnumrandung, wie bei gleichen Formen im Nationalpark (Val Müschauns). An beiden Orten lassen sich Steinstreifen beobachten, die am Stirnrand der Zunge einsetzen (vgl. Lit. 3, Abb. 45).

\section{THEORIE ZUR BILDUNG DER STEINWULSTRINGE}

Vergleicht man die Beobachtungen an den Amundsensteinringen (Fig. 14) mit verschiedenen Stadien der Steinringbildung auf dem Sverdrupplateau (Fig. $21 \mathrm{~d}$ und e), so läßt sich eine Hypothese über die Entstehung der Steinwulstringe aufstellen (Fig. 21):

a) Ausgangsstadium ist eine Fläche mit mehr oder weniger einheitlicher Schuttbedeckung, wobei zwischen den Trümmern da und dort Feinerde angereichert ist. Unregelmäßig verteilt können einige Pflanzenpolster auftreten.

b) Durch Frosteinwirkung werden Beulen gebildet.

c) Steine werden durch Mikrosolifluktion in der Auftauperiode vom Beulenzentrum radial wegtransportiert, Feinerde wird an der Oberfläche sichtbar.

d) Mit der Zeit bildet sich um die Feinerdebeule ein Steinkranz. Durch Auffrieren gelangen immer neue Steine an die Oberfläche. An der wenig bewegten Beulenbasis kann sich die Vegetation weiterentwickeln.

e) Mit der Zeit wächst der Steinkranz - Frostsprengung zerlegt seine Steine, fortschreitendes Auffrieren fördert neue - und wird durch Frostschub und Solifluktion bis zur Beulenbasis auf die Vegetation geschoben.

f) Da mit der Zeit der Vorrat an Steinen in der Feinerdesäule erschöpft ist, können immer weniger solche auffrieren. Die noch vorhandenen werden durch Mikrosolifluktion zusammen mit Feinerde bis an den Steinwulst bewegt. 
g) Am Widerlager des schon vorhandenen Steinwulstes stauen sich Feinerde und nachfolgende Steine.

$\mathrm{h}$ und i) Je nach Abstand der Feinerdezentren voneinander entstehen 3 Fälle: bei großem Abstand bleiben die Steinwülste getrennt durch einen bewachsenen Graben, bei kleinerem Abstand können sich die Wülste berühren ( $h$, Moose und Flechten siedeln sich gerne in der Trennungslinie an). Im Extremfall schmelzen 2 Steinwülste zu einem zusammen (i).

k) Nach der Frostwirkung sinken die Feinerdebeulen zusammen. Damit sacken auch die innern Wülste nach. Bleibt es bei einer ausgedehnten Ruhephase, so siedelt sich die Vegetation besonders in der Nische zwischen der Feinerdefläche und dem inneren, feinerdereichen Wulst an, der mit der Zeit als eigentlicher Vegetationswulst erscheint.

Diese Entwicklung wird durch Ruhephasen immer wieder unterbrochen, während denen die Feinerdebeule zusammensinkt. Jede erneute Aufwölbung fördert die Mikrosolifluktion. Ruhephasen treten auf:

- jeden Sommer, wenn im Boden kein Wasser mehr vorhanden ist oder kein wirksamer Frost auftritt

- während längeren Zeiträumen, die sich über Jahre erstrecken können. Die Form kann später wieder aktiviert werden und ausreifen. Zumindest eine solche Ruhephase muß für die Amundsensteinringe angenommen werden im Hinblick auf die humose Schicht unter den Steinwülsten (Fig. 14).

Beim Betrachten von Fig. 14 fallen innerhalb der Feinerdesäule Strukturen auf. Sind diese eine Folge der Bewegungen in der Feinerde? Auffallend ist ferner, wie sich die Kiesmasse zwischen den beiden Feinerdesäulen gegen oben verengt, ebenso die symmetrische Lage von Feinerdelinsen.

\section{OSTHANG UND TALBODEN DES LONGYEARDALEN}

Die Halden aus kantigem, oft plattigem und lose gelagertem Schutt tragen keine Muster. Von einigem Interesse sind lediglich die Verhältnisse im obersten Abschnitt der Hangkrone (Fig. 20 b). Der schmale Grat (1) ist im Sommer kaum begehbar: Er ist von vielen Rissen durchsetzt, beim Daraufstehen lösen sich einzelne Brocken und stürzen ab. Die losgebrochenen Trümmer sind locker gelagert (2). Auf sie folgen Schneeflecken (3) mit einzelnen heruntergekollerten Steinen. Diese beliefern die anschließende Feinerde (4) mit Wasser. Dabei entwickelt sich Fließerde, die am Rand des Schneefleckens 2-3 cm mächtig ist. Schon $10-12 \mathrm{~m}$ weiter hangabwärts sinkt man über Schuhtiefe ein. 3 Wochen früher (27.6.1956) war die Fließerde auf der Verflachung oberhalb Pt. 371 derart, daß jegliches Stehen darauf unmöglich war. Jetzt ist die Oberfläche dort trockener und begehbar.

Im Raum (4) und (5) können folgende Formen beobachtet werden:

(4) schmale Vegetationsbänder, parallel zur Fallinie angeordnet und auf trockenen Stellen Pflasterboden.

(5) girlandenartige Vegetationsbogen, die vegetationsfreien Rückenflächen tragen ein Krümmelrelief, das an Kammeiswirkung erinnert, oder Zellenboden.

Darunter setzt die eigentliche Schutthalde ein. In ihrem obersten Abschnitt ragen oft Bastionen des Anstehenden heraus, die wie der Grat (1) stark zerklüftet sind.

Die Sohle des Longyeardalen ist in ihrer ganzen Breite mit Schottern überzogen, in denen viele Wasserläufe sich ihren Weg zum Meer bahnen. Auf diesen Schottern fanden sich weder Strukturböden noch Fließerdeformen. $4 \mathrm{~km}$ vom Meer entfernt liegen im Longyeardalen und seinem östlichen Seitental der Longyear- und der Larsbreen. Deren Endmoränen ziehen von einer Talflanke zur andern und bilden hohe, steile Wälle. In ihrer Nähe trifft man auf älteren Moränen oder auf 'Terrassen, welche die Schotterflur überragen, Girlanden und Feinerdebeulen. Auf den Endmoränen selbst kann gelegentlich die ruckartige Bildung kleiner Solifluktionszungen beobachtet werden. 


\section{UNTERSUCHUNGEN IN DEN BÜNDNER ALPEN VAL SASSA UND VALLETTA IM NATIONALPARK}

(Fig. 22 und 23, kartiert 11.-14.7. 1958)

Die in diesen Höhen vorherrschende mechanische Verwitterung liefert kantigen Schutt, der die Talsohle mit wenigen Ausnahmen - glazial überarbeitete Felsriegel beispielsweise - bedeckt und im Zeitpunkt der Kartierung wenigstens oberflächlich trocken war. Schutthalden ziehen sich weit an den Hängen hinauf; unterhalb des Blockstromes im Val Sassa (Lit. 2) überschneiden sich die Schuttkegel beider Talflanken auf der schmalen 'Talsohle; der Bach fließt meist unsichtbar im grobblockigen Schutt der Schuttkegelränder. Von der Blockstromstirn aufwärts trifft man die Schuttkegelstirnen nahe den Blockstromflanken; stellenweise stauen sie sich am Blockstrom und werden von diesem talwärts gedrängt.

Detritusbildungen in situ dagegen sind infolge der Steilheit des Geländes und mangels Verflachungen selten. Man trifft sie etwa im Vorfeld eines Blockstroms oder Gletschers an jüngsten glazialen und fluvioglazialen Ablagerungen.

Fig. 22 Profil durch das Val Sassa. Profilverlauf: (Landeskarte Blatt 259) Pt. 1939-2098 Koord.

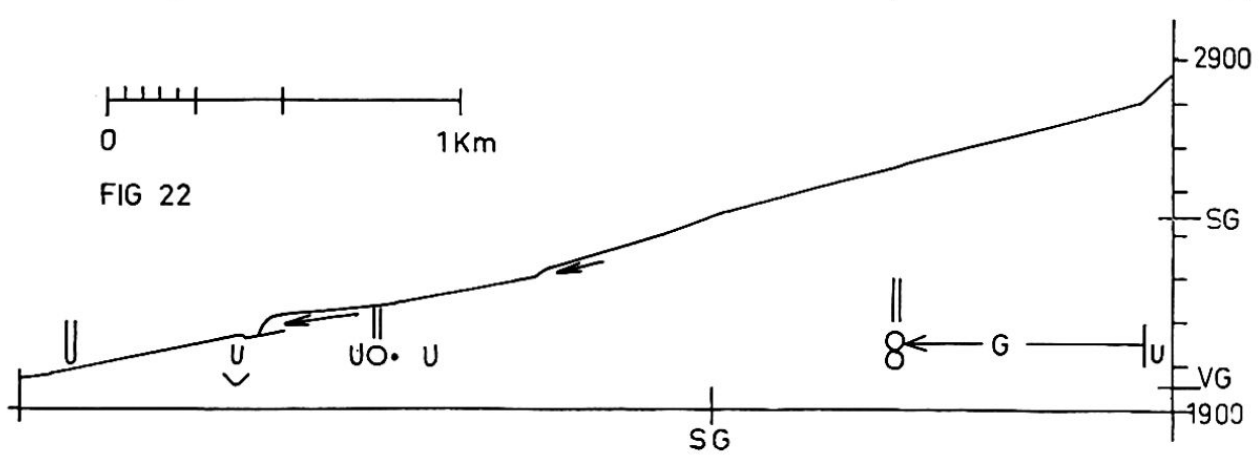
$804275 / 166375-2857$ (Alle Profile aus den Alpen sind nicht überhöht.) - Die unterste eingezeichnete lange und schmale Fließerdezunge liegt nicht im Profil sondern auf der rechten Talseite. Die Hänge sind arm an solchen Formen. - G Gletscher SG Schneegrenze; kurze Pfeile: Blockstromstirnen.

Fig. 23 Profil durch Valletta. Profilverlauf: Pt. 1832 - Koord. 804450/170400 - 2469 - Richtung Piz Quattervals. Pfeil:

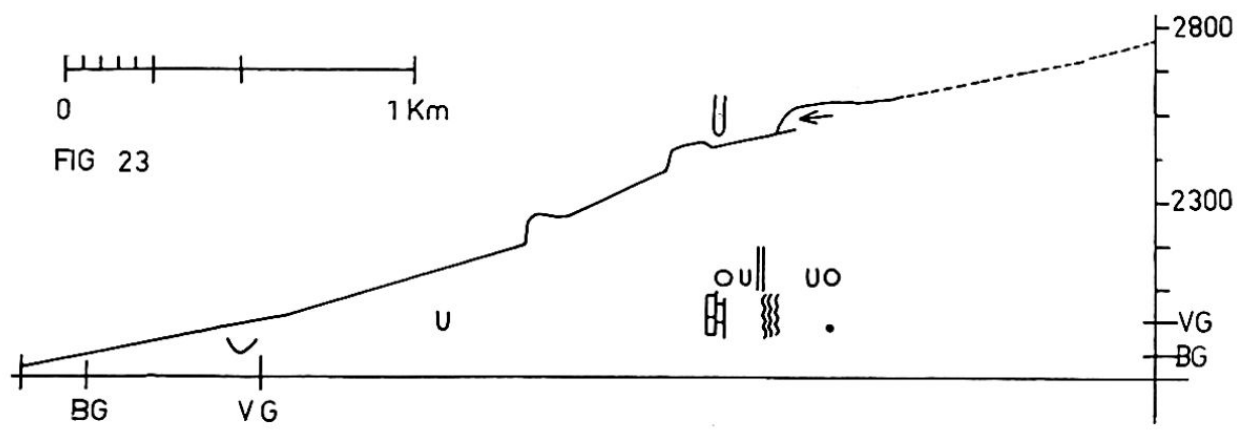

Blockstromstirn; gestrichelt : nicht kartierbare Oberfläche (Schnee); VG Vegetationsgrenze BG Baumgrenze. Wie im $\mathrm{Val}$ Sassa findet sich auch hier auf der rechten Talflanke eine schön ausgebildete, lange und schmale Fließerdezunge.

Fig. 24 Profil durchs Val Müschauns. Profilverlauf: (1858) - 801300/165850 - 801750/166150 -

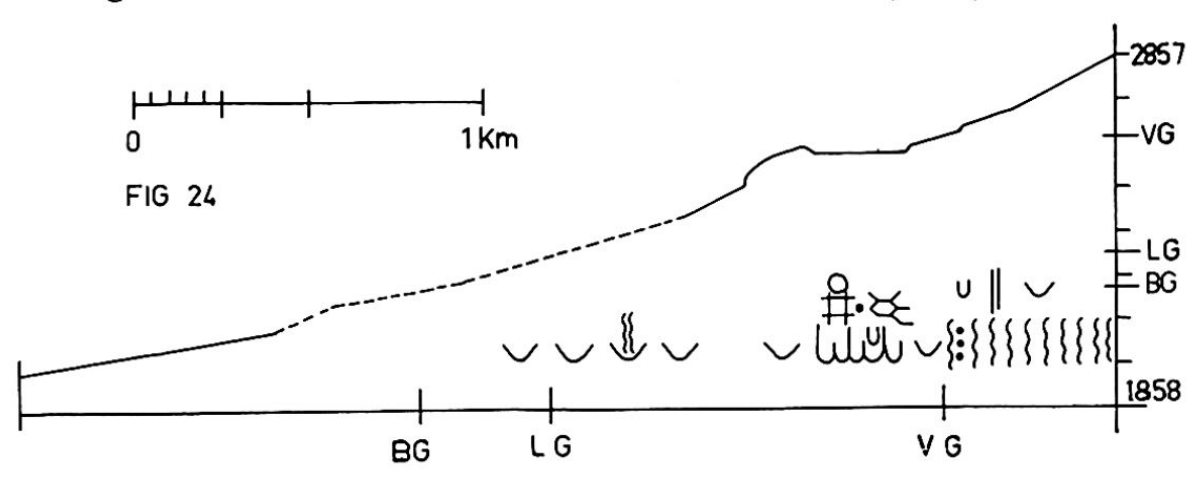
$2601-803025 / 165900$ 2857 (Fuorcla Val Sassa) LG Legföhrengrenze; gestrichelt: Profil nicht in der Fallinie. 
Die geschlossene Vegetation - Nadelwald, Legföhren, Rhododendron hirsutumBestände und Wiesen - zieht sich vom Haupttal (Val Cluozza) nur wenig weit in die beiden Seitentäler hinauf, auf der linken Sassatalseite etwa bis zur Kote 1960 m. Wir treffen daher in beiden Tälern vornehmlich nackte, humus- und vegetationslose Lockerschuttmassen.

Mitte Juli 1958 lagen im Talgrund über 2000 m noch einzelne Schneemassen; auf den Blockströmen waren die Schneeflecken auf langgezogene Vertiefungen zwischen Wülsten beschränkt. Dadurch wurde das stark belebte Kleinrelief der Blockstromoberfläche deutlich sichtbar.

Makroformen von Strukturböden, Steinstreifen und -ringe treten v. a. auf den Blockströmen nur vereinzelt auf, die Ringe gelegentlich in prägnanter Ausbildung mit schwach aufgewölbtem Feinerdezentrum und eingesenktem Steinrahmen. Auf einer Moräne des Gletschers im Val Sassa fand sich einer jener seltenen Steinringe, in dessen Zentrum ein großer Stein die Stelle der Feinerde einnahm (2580 m, vgl. Abb. 2, Lit. 5 und Abb. 7/5, Lit. 6). Auf den Blockströmen sind die Makroformen auf Stellen mit feinkörnigem Schutt und nur dünner Steindecke beschränkt. Übergänge von Steinringen zu langgezogenen Formen bis zu Schuttgirlanden, deren talseitiger Rand von groben, kantigen Trümmern gesäumt wird, lassen sich dort beobachten.

Die stromlinienartig verlaufenden Erdstreifen bedecken so große Flächen, wie sie mir bisher in den Alpen nie begegnet sind. Ihre flächenhafte Ausdehnung und ihre Länge - bis $10 \mathrm{~m}$ - läßt sich mit Erdstreifenmustern der Blomstrandbucht auf Spitzbergen vergleichen.

An der linken Talseite des Val Cluozza, auf der Höhe des Fußweges zwischen der Einmündung des Valletta und dem Val Sassa $( \pm 1850 \mathrm{~m})$ können auffallenderweise keine Girlanden beobachtet werden, treten doch sonst im Val Cluozza wie in andern Bündnertälern einzelne dieser Fließformen auch unterhalb der Baumgrenze auf.

\section{VAL MÜSCHAUNS}

(Fig. 24, kartiert 15.7.1958 und 21.9.1952)

Am 15. Juli 1958 war der Boden auch an seiner Oberfläche noch um 13 Uhr oberhalb 2740 m gefroren. Kammeis und Solifluktion ließen sich daher oberhalb dieser Kote nicht beobachten. Da der Boden nachts auch noch in tieferen Lagen oberflächlich gefroren war, hatte sich in der vergangenen Nacht Kammeis erst unterhalb einer Höhe von ca. $2400 \mathrm{~m}$ gebildet. Wenig mächtige aktive Fließerde dagegen trat am frühen Nachmittag unterhalb $2700 \mathrm{~m}$ in Erscheinung. - «Arktisch» anmutende Fließerdemassen mit reichhaltiger Musterung liegen se Pt. 2601. Darauf finden sich Schuttzungen (abgebildet in Lit. 3, Abb. 45) mit teilweise kantengestellten Steinen in ihrer Stirnumrandung, Polygone (abgebildet in Lit. 3, Abb. 20), einige vereinzelte und nicht besonders prägnant ausgebildete Steinringe, wenige, aber schön entwickelte Miniatursteinringe mit aufgewölbten Feinerdezentren, Zellenboden mit 5-10 cm Seitenlänge der Polygone und teilweise feiner Steinspreu in den Rissen. Einzelne Fließerdezungen wurden um die Mittagszeit von schmelzenden Schneeflecken mit Wasser gespiesen. Vielerorts lag Schmelzwasser, das von der übersättigten Fließerde nicht mehr aufgenommen werden konnte. In 20-30 cm Tiefe war der Boden stellenweise noch gefroren.

Die Erdstreifen unterhalb der Fuorcla Val Sassa bedecken noch größere Flächen als im Valletta. Über $2660 \mathrm{~m}$ sind sie besonders gut entwickelt und dominieren alle andern Formen. Ihr verbreitetes Auftreten wird durch größere Feinerdeflächen mit nur feiner Steinspreu begünstigt. Der stromlinienartige, für diese Bodenmusterung charakteristische Verlauf, mit dem sie größere Steine oder Pflanzenpolster umfließt, tritt deutlich in Erscheinung. Wo sie von der Sonne erreicht werden, sind die aufge- 


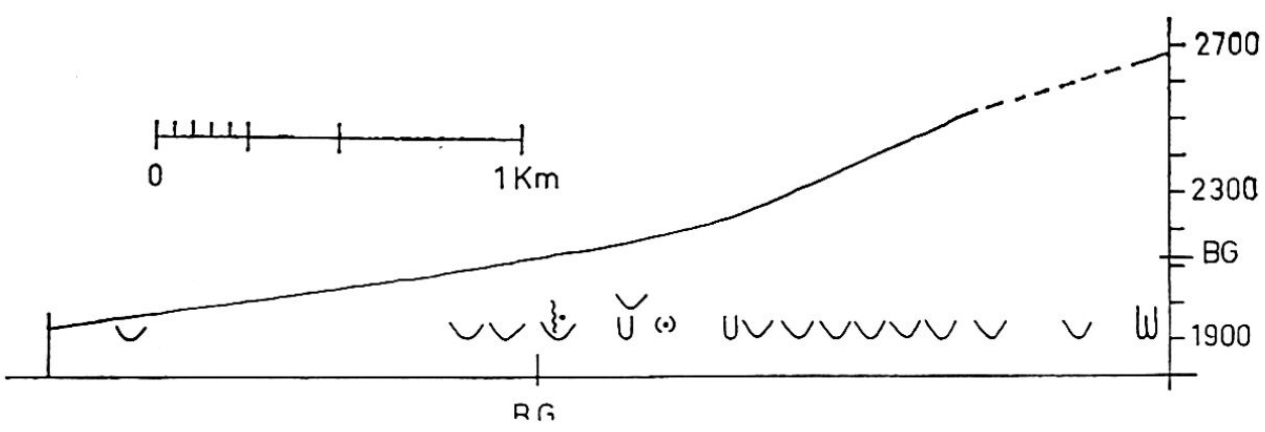

Fig. 25 Profil durch das Val dal Botsch. Profilverlauf: (1877) 2160 entlang dem Weg zur Fuorcla Val dal Botsch. Gestrichelt: Profil nicht in der Fallinie. (') Kammeiserdknospen.

quollenen Feinerdestreifchen feucht. Gelegentlich gehen die Steinstreifchen in ganz kleine Schuttkegel über, welche auf eine Auswaschung hinweisen.

Zwischen 2660 und $2700 \mathrm{~m}$ treten einige $10-20 \mathrm{~cm}$ breite Steinstreifen auf. Ihr Zwischenraum schwankt von $20-30 \mathrm{~cm}$. Nach ihren Dimensionen klassiert nehmen sie eine Mittelstellung zwischen den Erdstreifen und der Makroform der Steinstreifen ein. Im Verbreitungsgebiet der Girlanden trifft man Windsichelrasen und auf schwach gewölbten Kuppen tonsurierte Polster (vgl. Lit. 3, Abb. 1-4). Oft sind die Girlandenrücken durch Erdstreifen oder Zellenboden gemustert (vgl. Lit. 3, Abb. 32 und 33).

\section{VAL DAL BOTSCH}

(Fig. 25, kartiert 15.10.1958)

Über die Anordnung der Formen auf Hängen im östlichen Nationalparkgebiet gibt Fig. 25 Aufschluß. - 2 Tage vor der endgültigen Kartierung fiel Schnee. Unterhalb $2480 \mathrm{~m}$ schmolz dieser bis zum 15.10. wieder weg, sodaß die Oberfläche gut durchfeuchtet war. Trotzdem fanden sich kaum Spuren frischer Kammeiswirkung.

Formen der Makrosolifluktion sind auf Hängen unterhalb der Vegetationsgrenze die dominante Erscheinung. Von einem ganz kleinen Erdstreifenfeld in auffallend tiefer Lage $(2130 \mathrm{~m})$ und wenigen Kammeiserdknospen $(2190 \mathrm{~m})$ mit teilweise deutlicher Materialsortierung zu Miniatursteinringen $(2130 \mathrm{~m}$ ) abgesehen, fehlen Strukturbodenformen ganz.

Die Kartierung zeigt den Formwandel und die Änderung in der Dichte des Auftretens von Girlanden mit zunehmender Höhe besonders deutlich: im Wald, ab $1960 \mathrm{~m}$, treten vereinzelte Girlanden an steilen Hängen, besonders seitlich von Bächen, auf. Girlanden in klassischer Ausbildung (vgl. Lit. 3, Abb. 31 und 33) zieren dicht geschart die Hänge zwischen 2260 und $2320 \mathrm{~m}$, darüber sind sie teilweise stark auseinandergerissen (vgl. Lit. 3, Fig. 3b-d). Über 2400 m werden die Girlanden kleiner (ähnlich Abb. 36, Lit. 3, aufgenommen auf ca. $2560 \mathrm{~m}$ auf der $\mathrm{N}$ Seite des Munt la Schera). An der talwärts gerichteten Fläche der Girlandenstirn setzt Winderosion und auf entblößten Flächen Kammeis ein, sodaß Sichelrasen entsteht. Auf schwächer geneigtem Hang und in noch höheren Lagen - über $2520 \mathrm{~m}$ - sind die Girlandenrücken bei vielen Formen bewachsen.

Schön entwickelte Fließerdezungen (abgebildet in Lit. 3, Abb. 40 und 43) liegen auf $2650 \mathrm{~m}$. Dieses Ordnungsprinzip: optimale Zone der Girlanden zwischen 2250 und $2350 \mathrm{~m}$ und darüber große Fließerdezungen läßt sich auch in andern Regionen des Parks beobachten, wobei die Fließzungen in folgenden Höhen liegen:

E Hang Mt. la Schera

S Hang Mt. Chavagl

E Hang Mt. Chavagl

W \&SW Hang Mt. Buffalora

Val Müschauns, $N$ Exposition

(Cassonsgrat um $2440 \mathrm{~m}$

$2440 \mathrm{~m}$ (Lit. 3, Abb. 44)

um $2450 \mathrm{~m}$ (Lit. 3, Abb. 44)

2 370-2 $380 \mathrm{~m}$ (Lit. 3, Abb. 37)

$2580 \mathrm{~m}$

$2600-2640)$ 


\section{CASSONSGRAT}

(Fig. 26, kartiert 31.8.1958)

Mit Ausnahme der Bülten - die, nach dem heutigen Stand ihrer Erforschung zu schließen, in den Alpen nicht als rezente Bildungen $\mathrm{zu}$ betrachten sind (TROLL, Lit. 9, S. 549 und Furrer, Lit. 4) - findet man auf dem Cassonsgrat (Il Fil, 2620-2690 $\mathrm{m})$ alle mir aus den Alpen bekannten Solifluktionsformen in buntem Wechsel beisammen:

Steinnetzboden, dessen Polygone und sortierte Steine nach Größe und Form vielen Vertretern der Arktis nicht nachstehen, und Steinkreise, deren Feinerdezentren 40$70 \mathrm{~cm}$ im Durchmesser messen. Völlig vegetationsfreie Formen wechseln mit Steinrahmen, an denen sich Pionierpflanzen angesiedelt haben. Nach dem Fehlen von Vegetation auf den Feinerdezentren und dem breiigen Zustand der in wenigen $\mathrm{cm}$ Tiefe sehr kalten Feinerde zu schließen, handelt es sich bei diesen Frostgefügeformen um aktive Formen. Steinstreifen können ne Pt. 2678 deutlich als Formen der Hangsolifluktion erkannt werden: grüne, oft senkrecht stehende plattige Steine der Streifen fließen mit ihrem Untergrund - Fließerdezungen, Wanderschuttdecken - auf nur schwach geneigten Flächen teilweise über weißen anstehenden Fels. Die Streifen folgen dem stärksten Gefälle. Sie sind daher nicht etwa schnurgerade, sondern sie ziehen sich vom Hang zum Muldenboden und biegen in dessen Längsachse ein.

Miniaturformen, besonders die Ringe, werden beim Kartieren häufig übersehen. Trotzdem scheinen sie zwischen 2620 und $2660 \mathrm{~m}$ gegenüber den andern Formen zurückzutreten, obschon auch Flächen mit genügend feinkörnigem Schutt vorhanden sind. Flächenhafte Musterung durch Feinerdestreifen in großem Ausmaß wie beispielsweise im Val Müschauns über $2660 \mathrm{~m}$ fand ich keine. Vergleicht man ferner den Ausbildungsstand dieser Formen mit jenen vom Val Müschauns, so fällt deutlich auf, daß die höher gelegenen des Nationalparks viel prägnanter gezeichnet sind. Einmal mehr wird die Beobachtung bestätigt, daß die optimale Zone für das Auftreten der Miniaturformen um 2700 m liegt.

Im östlichen Abschnitt des Grates, am Aufstieg zu Pt. 2693,9 wird die Vegetation dichter. Obschon, verursacht durch den Tourismus, gewisse Störungen auftreten, kann man an jenem Hang das absolute Vorherrschen von Solifluktionszungen feststellen, während Strukturbodenformen fehlen.

Der bisher erst einmal im Nationalpark gefundene Kuchenboden (Lit. 3, Abb. 51) gliedert auf dem Cassonsgrat die Oberfläche einer Wanderschuttdecke. Der Kuchenumriß kann polygonartig oder annähernd kreisrund sein, bei schwacher Hangneigung

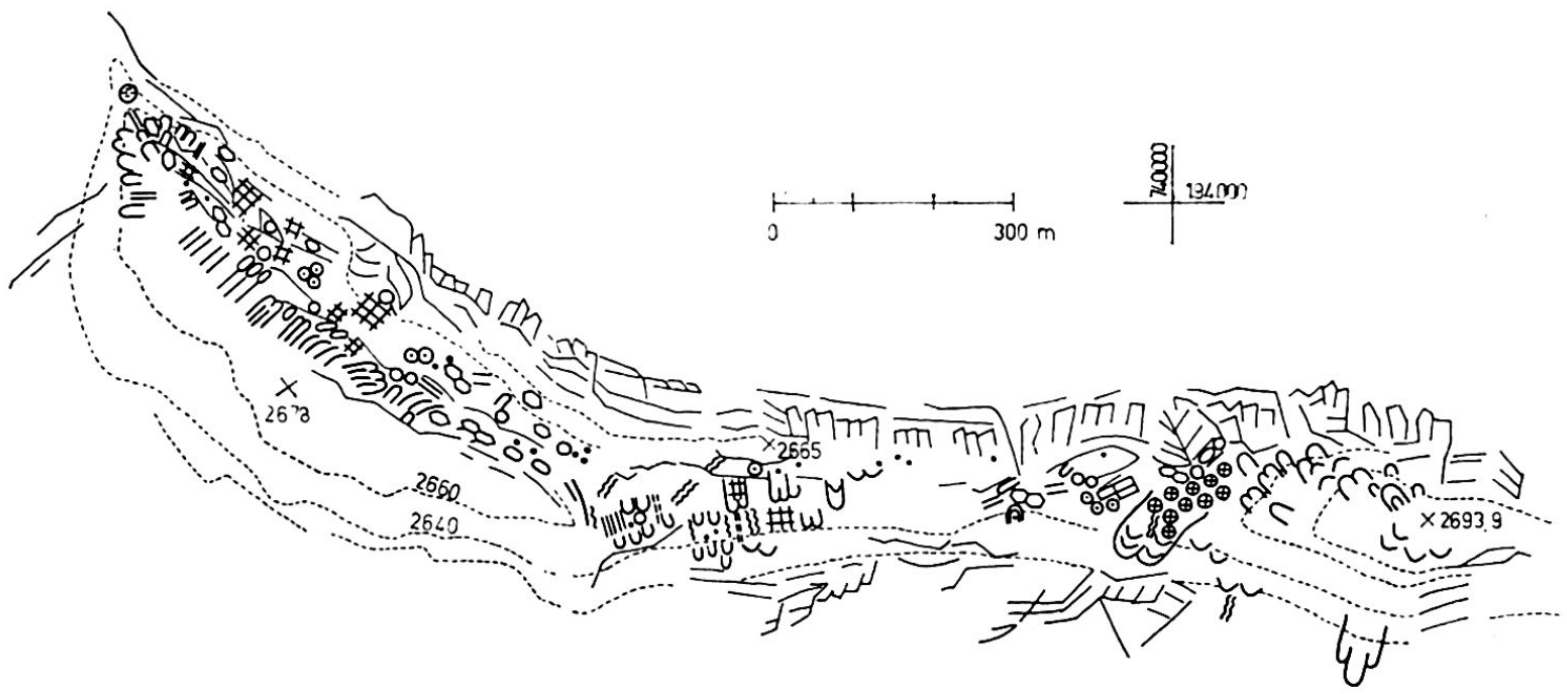

Fig. 26 Der Formenschatz des Cassonsgrates (Landeskarte Blatt 247 Il Fil) 
oval mit deutlich beobachtbaren Übergängen $\mathrm{zu}$ wohlgeformten Girlanden. Die \pm $1 \mathrm{~m}$ im Durchmesser messenden Formen sind voneinander durch oft kaum schuhbreite und -tiefe Rinnen, die ein dichtes Vegetationskleid tragen, getrennt. Die plane Kuchenoberfläche ist normalerweise vegetationslos, nur selten treten Formen auf, die völlig überwachsen an Bülten erinnern. Nach der Schneeschmelze sind die Kuchenzentren wasserdurchtränkt und breiig, in den anderen Jahreszeiten an der Oberfläche hart. Das spärliche Beobachtungsmaterial läßt vorläufig noch keine Schlüsse auf die Entstehung dieses Typs zu. Sind es durch Kammeis und Winderosion (Rasenschälen) aufgerissene Bülten oder sind sie aus weitmaschigem Zellenboden entstanden, wobei sich in den Rissen Vegetation ansiedelte und die Hangsolifluktion die Risse erweitert hat? (vgl. Lit. 3, Seite 268).

\section{HÖHENLAGE VON MINIATURFORMEN (ohne Zellenboden)}

Die Ergebnisse beruhen hauptsächlich auf Beobachtungen von Erdstreifen; die Steinringe sind weniger geeignet, da sie ihrer Kleinheit wegen häufig übersehen werden und zudem flächenhaft nicht so in Erscheinung treten wie die Erdstreifen . - TroLL (Lit. 9, Seite 655) stellt fest, daß der «tropische» Miniaturtyp vorwiegend über 2700 m auftritt. Mir scheint, daß diese $Z$ ahl für Bünden etwas tiefer anzusetzen sei:

Im Val Müschauns dominiert der Miniaturtyp über $2660 \mathrm{~m}$ (WSW Exposition). Bis zur Vegetationsgrenze $(2620 \mathrm{~m})$ sind die Erdstreifen

$2660-2850 \mathrm{~m}$ $2620 \mathrm{~m}$ weiterhin prägnant ausgebildet und allgemein verbreitet. Einzelne Vorkommen, nur kleine Flächen bedeckend, in $2360 \mathrm{~m}$ (Fig. 24).

Der Übergang in die Zone ihres optimalen Auftretens wird an diesem Beispiel deutlich. Man spricht besser von einem Grenzsaum anstelle von «unterer Strukturbodengrenze». ( $\mathrm{Zu}$ Vergleichszwecken kann letztere im Müschauns auf $2660 \mathrm{~m}$ festgelegt werden).

Valletta (Fig. 23): Nach der Größe der gemusterten Fläche, Länge der Streifen und Qualität der Ausbildung sind die Vorkommen den höchstgelegenen im Val Müschauns gleichzusetzen (N Exposition).

Einzelne prägnant ausgebildete Vorkommen, die aber nur kleine Flächen bedecken, wurden beobachtet:

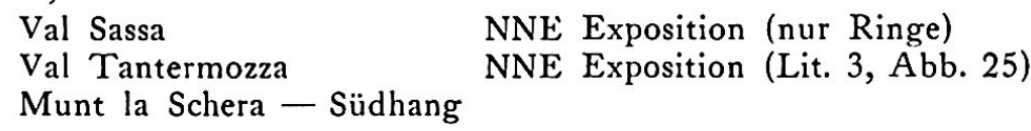

S Exposition auf dem Grat

SE Exposition (Miniatursteinnetze)

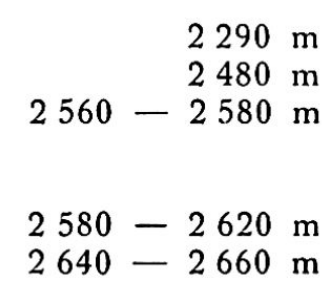

Piz Beverin (Lit. 4)

- se Pt 2825

- Alp Nursin

Die noch kleine Anzahl bekanntgewordener Vorkommen schon zu Schlüssen auf den Zusammenhang zwischen Höhenlage und Exposition verwenden zu wollen, scheint, besonders auch im Hinblick auf den starken räumlichen Wechsel des Mikroklimas, verfrüht. Immerhin sei darauf hingewiesen, daß in den nach $\mathrm{N}$ gerichteten Tälern des Piz Quattervals (3164.8) - Tantermozza, Valletta, Sassa - die Miniaturfrostmuster in tieferen Lagen zu beobachten sind, als an seinem Südhang (Müschauns).

\section{POSERS ERGEBNISSE UND DIE VERHÄLTNISSE IN BÜNDEN}

\section{Strukturböden}

Poser faßt in seiner Arbeit «Die Periglazial-Erscheinungen in der Umgebung der Gletscher des Zemmgrundes» (Lit. 8) leider alle Strukturbodenarten in einer einzigen 
Signatur zusammen. Er unterläßt es ferner, die Miniaturformen beim Kartieren auszuscheiden. Untersucht man auf seiner Karte die Verbreitung der Strukturbodenformen, so ergibt sich folgendes:

1. Sie fehlen auf fluvioglazialen Bildungen der Gletschervorfelder

2. Sie treten einerseits

a) in einem engen Höhenbereich in den Gletschervorfeldern und

b) anderseits wesentlich höher auf:

a) Waxegg-Kees

Horn-Kees 2000-2050 m, innerhalb des Moränenkranzes von 1920; vereinzelt bis gegen 2100 und ferner zwischen den Koten 1900 und 1950 innerhalb des Moränenkranzes von 1850.

etwas über $2050 \mathrm{~m}$.
Schwarzenstein-Kees $2100-2150 \mathrm{~m}$ (von diesen ist ein Ausschnitt eines Steinnetzes bei 'Troll (Lit. 9, S. 652) abgebildet, das Troll als undeutlich bezeichnet).

b) außerhalb der Gletschervorfelder, nach den Signaturen zu schließen nur wenige Formen:

SW und SE Schwarzsee

$2450-2500 \mathrm{~m}$

Grat vom Krähenfuß nach SW ansteigend $2800-2850 \mathrm{~m}$

Poser weist darauf hin, daß das Gebiet größter Formenhäufigkeit und zugleich klarster Formenprägung die Gletschervorfelder seien (S. 158), wobei die gletscherfernsten, untersten Strukturböden den Eindruck erwecken, bereits Ruheformen zu sein. Ferner macht er auf einen Formenwandel nach Größenordnung und Art der Musterung mit zunehmender Höhe aufmerksam: Steinkreise der Gletschervorfelder messen im Durchmesser $1 / 2$ bis $3 \mathrm{~m}$ und Sortierungstiefen bis $35 \mathrm{~cm}$. Weiter höhenwärts werden diese Formen sehr bald von Miniaturformen abgelöst, wobei es der Autor leider unterläßt, diese näher zu beschreiben. In den höchsten Regionen seines Untersuchungsgebietes schließlich, wo keine Feinerde mehr zur Verfügung steht, werden die Miniaturformen durch Muster aus kantengestellten Scherben abgelöst.

Schon 1944 hat Troll (Lit. 9) die eben skizzierten Ergebnisse als Verbreitungsprinzip der Strukturböden in den Alpen erkannt. Er spricht (S.655) vom größeren polaren Typ vorwiegend in tieferen Lagen von $2200 \mathrm{~m}$ aufwärts und dem tropischen Miniaturtyp vorwiegend über $2700 \mathrm{~m}$. Die Ergebnisse meiner Feldarbeit sollen zeigen, inwiefern diese Theorie, der keine Kartierung beigegeben ist, für die Verhältnisse in Bünden zutrifft.

\section{Standort der Strukturböden in Bünden}

Die Kartierung von Valletta und Val Sassa zeigen, daß Täler mit nur noch kleinen Gletschern strukturbodenarm, dagegen reich an Formen der Makrosolifluktion sind. - Was für Resultate ergibt eine Begehung eines Gletschervorfeldes, bei dem Exposition und Höhenlage des Eisstromes ähnlich sind wie im Untersuchungsgebiet Posers? Zur Beantwortung sei das Morteratschgebiet (Engadin), Talboden und Hang links des Gletscherbaches gewählt:

Die jungen fluvioglazialen Bildungen sind wie im Zemmgrund - und soweit Resultate von anderen Gletschertälern der Alpen vorliegen - allgemein strukturbodenfrei, auch an Stellen, wo zwischen den Steinen reichlich Feinmaterial vorhanden ist. Dies trifft bei Morteratsch auch für jene Flächen $z u$, welche die Schotterflur überragen: Moränen und Hänge bis in $2050 \mathrm{~m}$ Höhe. An den Hängen, unterhalb dieser Kote, die Wald oder niedrige Vegetation tragen, lassen sich auch keine Girlanden oder andere Fließformen beobachten. Miniaturformen, beispielsweise auf Moränen, wo 
- wie mir scheint - der Boden zur Bildung von Feinerdestreifen geeignet wäre, fehlen ebenfalls.

Nur sehr wenige, nicht deutlich sichtbare Steinringe konnten festgestellt werden:

a) außerhalb der Endmoräne von 1878 auf $1910 \mathrm{~m}$ im Talboden: 2 stark überwachsene Steinringe mit bis kopfgroßen Steinen. Einer wies im Zentrum einen über kopfgroßen Stein als Kern auf, der an der Oberfläche sichtbar war. Sie erweckten den Eindruck von Ruheformen.

b) gletscherwärts der Endmoräne von 1878 :

1. 1920 m, inmitten von Gras und Alpenblumen ein Ansatz einer Steinringbildung von $40 \mathrm{~cm}$ Durchmesser. Im Zentrum war oberflächlich keine Feinerde sichtbar, hingegen sprang die Zunahme der Korngröße vom Zentrum nach außen in die Augen. Die kreisförmige Peripherie markierten faustgroße Steine, die aber noch keinen deutlich wahrnehmbaren Rahmen bildeten (ähnlich Abb. 3, Lit. 5).

2. $1950 \mathrm{~m}$, nahe der Gletscherstirn, wenige Steinringe, von denen sich 3 deutlich abzeichneten. Der schönste besaß einen Steinkern, welcher die oberflächliche Schuttspreu im Zentrum knapp überragte (Abb. 2, Lit. 5).

Nur 3 Steinringe mit einem oberflächlich sichtbaren Kern fand ich bisher in den Alpen (siehe Val Sassa). Troll (Lit. 9, S. 654) bemerkt, daß in solchen Fällen die Materialsortierung deutlicher sei als sonst. Er glaubt daher, daß bei der Bildung solcher Steinringe die stärkere Frosthebung größerer Blöcke - in diesem Fall des Steinkerns - im Spiel sei.

Die schönsten Strukturbodenformen, die zugleich größere zusammenhängende Flächen mustern, sind mir bisher in Graubünden fern von Gletschern auf Hochflächen bekanntgeworden, die im Hochsommer - von wenigen, die Böden mit Wasser durchtränkenden Schneeflecken abgesehen - schneefrei sind. Als Beispiele dienen der Cassonsgrat $(2650 \mathrm{~m}$ ), der Kleinfimberpaß (Unterengadin, $2650 \mathrm{~m}$, Lit. 6, Abb. 1119), einige Steinringe auf der Alp Nursin (2650 m, Lit. 5) und der Steinstreifenboden von Murtèr (2580 m, Lit. 3).

Ein Vergleich der Resultate aus dem Untersuchungsgebiet von Poser mit denjenigen aus Graubünden ergibt somit, daß weder in Bezug auf den Verbreitungsbereich der Strukturböden, noch bezüglich der Gletschervorfelder als «Gebiet größter Formenhäufigkeit und klarster Formenprägung» Übereinstimmung besteht. Auf Grund des gegenwärtigen Standes der Untersuchungen dürften kaum allgemein gültige Aussagen über die Verbreitung und den Standort der Strukturböden der Alpen gemacht werden können, vielmehr zeigt sich, daß weitere Kartierungen notwendig sind.

Überprüft man TROLLS Hypothese, so zeigt sich, daß sie als großzügige Generalisierung zutreffen mag, daß aber - wie die Kartierung von Cassons zeigt - durch das Nebeneinander von Makro- und Miniaturformen bedingt, die Verhältnisse komplizierter liegen. Am ehesten wird Troll der Zone der Miniaturformen gerecht, deren Untergrenze - ohne Berücksichtigung der Exposition - etwas unter $2700 \mathrm{~m}$ festgesetzt werden kann.

\section{VERGLEICHENDE BETRACHTUNG DER RESULTATE AUS DEN BEIDEN ARBEITSGEBIETEN SPITZBERGEN UND BÜNDNER ALPEN}

\section{STRUKTURBÖ DEN}

Unter den ausgereiften Steinringen, -polygonen und -streifen der Alpen gibt es zweifelsohne Vertreter, die jeden Vergleich in Bezug auf ihre Dimensionen, äußere Form und Bau, Vollkommenheit der Ausbildung, Grad und Tiefe der Materialsortierung mit gleichen Typen aus den mir bekannten Regionen Spitzbergens aushalten. Hingegen treten in der Arktis darüber hinaus größere Formen auf, bei denen auch 
größere Blöcke in die Materialsortierung miteinbezogen sind. Außerdem fehlen den Alpen Ringe mit prägnantem Steinwulst (vgl. Amundsenringe).

Polygondurchmesser von $260 \mathrm{~cm}$ bei Steinnetzwerk beobachtete Poser (Lit. 8, S. 163) zwischen Moränen der Gletscherstände von 1850 und 1890. Mein größter Fund, dessen Diagonalen 2,7-3 m maßen, lag auf horizontaler Fläche und scheint durch keine Hangsolifluktion deformiert. So große Formen in den Alpen sind Ausnahmen. «Riesenformen» stellen sich bei uns eher unter den Streifen ein. Ein solcher im Fimbergebiet erinnert mit seiner Länge von über $30 \mathrm{~m}$, seiner Breite von über $1 \mathrm{~m}$ und seinen kantengestellten Steinen, von denen einige über Durchmesser bis $50 \mathrm{~cm}$ verfügen, stark an einen Streifen Ny Alesunds (Lit. 6, Abb. 19). Zur Zeit der Schneeschmelze fließt im arktischen wie im alpinen Vertreter viel Wasser talwärts. Gleichzeitig verläuft auch die Oberfläche des gefrorenen Bodens bei beiden gleichsinnig: Die Feinerdebänder $z$ wischen den Steinstreifen sind noch beinahe bis an die Oberfläche gefroren,während unter den letzteren die gefrorene Zone tiefer liegt (Fig. 4).

Der Grad der Aufwölbung von Feinerdezentren, wie er in Spitzbergen im Sommer zu beobachten ist - im Extremfall etwa auf dem Sverdrupplateau - übersteigt alles, was aus den Alpen bekannt ist.

Übereinstimmung im Bau alpiner und arktischer Formen können gelegentlich bis ins Detail nachgewiesen werden: Fig. 2 zeigt, daß die Frostbodenoberfläche im Sommer unter Steinringen Spitzbergens gegensinnig zur Feinerdeoberfläche, uhrglasförmig, gewölbt ist. Das bisher einzige Profil durch ein Steinpolygon der Alpen, bei dem ich den Frostboden beobachten konnte, zeigt diesen gegensinnigen Verlauf ebenfalls (Lit. 6, Abb. 10). - In Spitzbergen wie in den Alpen fällt unter Steinrahmen häufig eine Rinnenauskleidung mit feinen Steinchen und weitgehende Kantenstellung plattiger Steine in den Rahmen auf (vgl. Fig. 5 und Lit. 6, Abb. 10).

Deformation von Steinringen zu -ellipsen und Übergänge in -streifen sind in beiden Regionen zu beobachten, nur traf ich Übergangsformen im Norden häufiger.

\section{MINIATURFORMEN}

Erdstreifenboden mit prägnanter, regelmäßiger Zeichnung der Bodenoberfläche, seinem charakteristischen stromlinienförmigen Verlauf um Hindernisse und dem knospenartigen Durchbrechen der Schuttspreu ist auf Photographien aus dem Münschauns und von der Blomstrandbucht nicht auseinanderzuhalten. Ihre Bildung mit Hilfe von Kammeis, die in den Alpen nachgewiesen wurde (Mohaupt, Lit. 7, Furrer, Lit. 3, S. 240), konnte im Norden nicht beobachtet werden. Dagegen wurde auf der Blomstrandhalbinsel der Einfluß der Hangsolifluktion auf lange Erdstreifen besonders schön sichtbar: Jeder Richtungsänderung des stärksten Gefälles - bei nur minimen Hangneigungen - folgen diese Streifen in großradigen Bogen.

Übereinstimmung in beiden Untersuchungsgebieten herrscht auch beim Zellenboden, mit und ohne Steinfüllung der Risse, sei es auf Feinerdefeldern von Makroformen, auf Rücken von Fließerdemassen oder auf gewöhnlichem, nicht durch andere Formen gemustertem Boden.

\section{FLIESSER DEF OR MEN}

Girlanden, Fließerde- und Schuttzungen treten auf geneigten Flächen in beiden Untersuchungsregionen auf. Unterschiede in der Ausbildung der Formen bei gleicher Neigung der Bodenoberfläche in den Alpen und in Spitzbergen konnten nicht nachgewiesen werden.

Die Großformen - Fließerdezungen - mit hangaufwärtsgreifenden, ungefähr parallelen, vegetationsbedeckten Rändern und deutlich entwickelter Zungenform sind im Nationalpark eher schärfer ausgeprägt als im Norden. Unterschiede ergeben sich hauptsächlich beim Vergleich der Stirnregionen: Der scharfe Absatz gegenüber der 
Umgebung, der häufig durch erneutes Einrollen der Vegetation charakterisiert ist (vgl. Lit. 3, Abb. 41), tritt bei den Formen in Spitzbergen weniger ausgeprägt in Erscheinung. Dort kann dagegen die Stirnkontur von breiten Steinsäumen begleitet sein. Die Rückenmusterung durch kleinere, aufsitzende Schuttzungen und Girlanden tritt in beiden Regionen auf.

Die im Vergleich zum Nationalpark wenigen Girlanden Spitzbergens weisen dieselben Variationen auf wie in den Alpen. Im Norden wie bei uns verlieren die Rasensäume bei zunehmender Hangneigung den Kontakt mit ihren höhergelegenen Nachbarn. Bau und Form, Bewachsungsverhältnisse und Musterung der Rücken sind identisch.

\section{VERBREITUNG UND STANDORTE DER UNTERSUCHTEN FORMEN}

Dem Nachweis gleicher Typen im Norden wie im Hochgebirge Bündens sei eine vergleichende Betrachtung über Verbreitung und Standorte derselben in beiden Regionen angefügt:

Feldbegehungen ergeben, daß unsere Makroformen der Strukturböden nicht so allgemein verbreitet sind wie im untersuchten Gebiet der Arktis. Auch treten sie bei uns nur auf einigen kleinen Flächen so dicht geschart auf wie etwa auf dem weiten Sverdrupplateau oder im Gletschervorland $\mathrm{Ny}$ Alesunds. «Arktisch» dicht gemusterte Flächen wurden auf Kleinfimber $(2650 \mathrm{~m}$, Lit. 6) untersucht, als weiterer Beleg diene die vorliegende Kartierung des Cassonsgrates (2620-2660 m, Fig. 26).

Junge, fluvioglaziale Ablagerungen sowie aktive Moränen sind ungünstige Standorte, Altmoränen und gletscherbachfreie Flächen dagegen, mit viel grobem Schutt Sverdrupplateau, Fimber, Cassons - können reich gemustert sein. In Tälern mit Gletschern - Valletta, Val Sassa, Morteratsch, Longyeartal - konnten nur vereinzelte Steinpolygone und -streifen nachgewiesen werden, während im Gletschervorland $\mathrm{Ny}$ Alesunds auf Altmoränen dicht gescharte Musterung vorliegt., Die Musterung im Gletschervorland des Zemmgrundes scheint, nach Posers Karte zu schließen, auch weniger dicht zu sein als bei $\mathrm{Ny}$ Alesund.

Erdstreifen als Vertreter der Miniaturformen spielen flächenmäßig im Norden keine derart dominierende Rolle wie etwa im Val Müschauns. Sie treten in Spitzbergen gegenüber den Makroformen eindeutig zurück, doch sind dort Miniaturformen in einigen Spielarten sicher nachgewiesen. Ich traf sie nur ganz nahe am Meerufer. Sie finden sich in lockerer, dünner Spreu feiner Steinchen über Feinerde, oft auf kaum einige $\mathrm{cm}$ mächtigen Böden. Die Standorte im Norden erinnern an jene der Alpen: die durch Rippen anstehender Dolomitfelsen gegliederte Gipfelzone des Munt la Schera oder die wenig mächtigen, einige $\mathrm{dm}^{2}$ messenden Bodenoberflächen $z$ wischen den Felsrippen auf Cassons bilden Standorte, die jenen der Erdstreifen westlich $\mathrm{Ny}$ Alesunds gleichen. Die Mehrzahl der Miniaturformen im Norden beobachtet man auf Feinerdeflächen von Erdbeulen, Strukturböden oder Girlanden. Sie können, wie an Feinerdebeulen $\mathrm{zu}$ beobachten ist, mit der Großform oder nach ihr entstehen.

Fließerdeformen scheinen im Norden wie bei uns identische Standorte aufzuweisen. Girlanden als weit verbreitete Flächenmuster treten im Norden, im Gegensatz zu den Hängen im Bünden, zurück. Blockströme wie im Nationalpark fand ich in Spitzbergen keine.

Vereinzelte Girlanden trifft man bei uns schon unterhalb der Waldgrenze; ihre optimale Entwicklung und Bedeutung als flächenhafte Musterung erlangen sie im Höhenbereich von 2200-2450 m, wobei die Zungen der großen Fließerdemassen ungefähr bis zum oberen Grenzsaum dieser Zone hinabreichen. Der eigentliche Girlandenbereich liegt somit tiefer als die schön entwickelten Makroformen von Cassons, Fimber und die Steinstreifen von Murtèr (2580 m, Lit. 3, S. 235 f).

Die meisten der untersuchten Formen Bündens liegen nach den bisherigen Beobachtungen : 
Girlanden

Fließerdezungen

Steinpolygone und -streifen

Erdstreifen
$2150-2650 \mathrm{~m}$ (Kernzone 2200-2450 m)

$2400-2650 \mathrm{~m}$

2600-2650 m (-2700 m) (ohne Berücksichtigung von Gletschervorfeldern)

$2600-2850 \mathrm{~m}$

Treten Makrostrukturbodenformen in den Alpen wohl ganz allgemein in 2 ver. schiedenen Zonen auf - einem tiefer liegenden, schmalen Gürtel um die Gletscherzungen und wesentlich höher, fern von den Gletschern, wo keine Vegetation den Frost und die Solifluktion in ihrer Wirkung auf den Verwitterungsschutt hemmt? Die vorliegenden Beobachtungen scheinen diese Theorie zu bestätigen.

In den untersuchten arktischen Gebieten reichen schön entwickelte Fließerdeformen und Strukturböden bis zum Meeresspiegel. In den Alpen dagegen nehmen die Fließerdeformen einen breiteren Höhenbereich ein als die Strukturböden. Von Strukturbodenformen um tiefliegende Gletscherzungen abgesehen, reichen die Fließerdeformen $400 \mathrm{~m}$ weiter talwärts. Diese Beobachtungen decken sich mit der Feststellung Posers, daß die untere, klimabedingte Strukturbodengrenze 400-500 m über der untern Solifluktionsgrenze liege (Lit. 8). Wer schon nach und während der Schneeschmelze die häufig kaum begehbare Fließerde - ein Erde-Schnee-Wassergemisch, das bei Vorhandensein eines Wasserstauers im Untergrund in den Alpen so fließfähig sein kann wie in der Arktis - erlebt hat, ist über die relativ große Höhenausdehnung der Fließerdeformen im Hochgebirge nicht erstaunt.

Strukturböden und Fließerdeformen sind im subnivalen Bereich beheimatet. Dieser dehnt sich zwischen der Waldgrenze, der Untergrenze der Girlanden, und der Schneegrenze aus. POSER und mit ihm die Kommission für Periglazialmorphologie der IGU ordnen Strukturböden, Girlanden und Schuttzungen den Periglazialerscheinungen zu. $\mathrm{Da}$ ich aber den Begriff «periglazial» für die gletschernahen eisfreien Räume reservieren möchte, und der behandelte Formenschatz nicht unbedingt an das Vorhandensein eines Gletschers gebunden ist, wird vorläufig nicht vom Begriff «subnival» abgerückt. Darnach richtet sich der Titel dieser Arbeit.

\section{ZITIERTE LITERATUR}

1. Bout, P.u. a.: Géomorphologie et Glaciologie en Islande Centrale. Norois, Revue Géographique de l'Ouest et des Pays de l'Atlantique nord, 8, 1955. - 2. Domaradski, J.: Blockströme im Kanton Graubünden. Ergebnisse der wissenschaftlichen Untersuchungen des schweizerischen Nationalparks, Band III (neue Folge) Nr. 24. - 3. Furrer, G.: Solifluktionsformen im Schweizerischen Nationalpark, Band IV (neue Folge) Nr. 29. - 4. Furrer, G.: Bodenformen aus dem subnivalen Bereich. Die Alpen, 6, 1955. - 5. Furrer, G.: "Steingärtchen» in den Alpen. Leben und Umwelt, II, 1955. - 6. Furrer, G.: Die Strukturbodenformen der Alpen. Geographica Helvetica, 4, 1955. - 7. Mонаupt, W.: Beobachtungen über Bodenversetzungen und Kammeisbildungen aus dem Stubai und dem Grödener Tal. Diss. Hamburg, 1932. - 8. Poser, H.: Die Periglazial-Erscheinungen in der Umgebung der Gletscher des Zemmgrundes (Zillertaler Alpen). Göttinger Geographische Abhandlungen, 15, 1954. - 9. Troll, C.: Strukturböden, Solifluktion und Frostklimate der Erde. Geologische Rundschau, Band 34, 7/8, 1944. - 10. Troll, C.: Die Formen der Solifluktion und die periglaziale Bodenabtragung. Erdkunde, Band I, 4/6, 1947.

\section{RECHERCHES SUR LA MORPHOLOGIE SUBNIVALE DU SPITZBERG ET DES ALPES GRISONNES}

Les bases du présent travail sont des recherches comparatives effectuées dans une région arctique et une région alpine.

On s'est efforcé de faire ressortir, à l'aide d'esquisses cartographiques, les différences et les ressemblances de la morphologie subnivale de ces deux régions et de sa situation respective.

Dans les sols polygonaux et striés, l'analogie de structure et de situation est frappante, à cela près que ces sols sont sensiblement moins étendus dans les Alpes, où d'une manière générale, les formes très grandes font d'ailleurs défaut (cf. fig. 2).

La fig. 3 représente un polygone de Svalbard, tel qu'il peut se rencontrer également dans les Alpes. Les formes miniatures, particulièrement bien développées en Suisse à une altitude comprise entre 2700 et $2800 \mathrm{~m}$, ont pu être également observées dans les îles du Spitzberg; mais elles y sont rares. 